

\title{
Experimental and Analytical Investigations of Seismic Pounding of Adjacent 14-Story Reinforced Concrete Buildings Damaged in 1985 Mexico Earthquake
}

\author{
Takahiro Chujo $^{1 *}$, Hiroshi Yoshikado ${ }^{2}$, Yuichi Sato ${ }^{3}$, Kazuhiro Naganuma $^{4}$ and Yoshio Kaneko ${ }^{5}$
}

\begin{abstract}
Seismic pounding of a 14-story reinforced concrete building, Nuevo León, damaged in the 1985 Mexico Earthquake is investigated by means of dynamic finite element analyses and cyclic loading tests of columns specimens. The building consisted of three adjacent units connected with $100-\mathrm{mm}$ wide expansion joints. It was thought that the poundings caused impact lateral forces and frictions that resulted in serious structural damage. This study attempts quantification of the impact lateral load by the following four steps.

(1) Two kinds of seismic response finite element analyses of a single unit of the building are conducted with /without simplified contact modeling with joint elements to approximately estimate the overall structural behavior.

(2) Cyclic load test of two column specimens that represent a column of the building. One of the specimens is a simple column while the other consists of four pounding units, to which the column contacts during loading. Comparison of the two specimens indicates that the contact induces additional lateral shear force to the column.

(3) Repeated cyclic responses of the two specimens are computed by static finite element analyses. The contact and friction behaviors are classified into normal and shear components to develop a constitutive model to be implemented into the two-node joint element.

(4) A finite element model of two partial building units connected with the two-node joint elements is subjected to seismic response analysis. The analysis result indicates that the pounding causes an impact load equivalent to $0.9 \%$ of the total weight of a building unit.
\end{abstract}

\section{Introduction}

On September 19, 1985, middle/high rise buildings around 10 to 20 stories in Mexico City were severely damaged by long period seismic motion of around two seconds. This damage was caused mainly by inadequate design code (AIJ 1987; Bertero 1986; Scholl 1989; Rodriguez et al. 1995, 1998). However, it has also been pointed out that the natural periods of these buildings were close to the predominant long period of the ground motion on the soft soil of Mexico City and caused resonance. The resonances of medium/high rise buildings during long period motion are of concern in large

\footnotetext{
${ }^{1}$ Engineer, Takenaka Corporation, Osaka, Japan. *Corresponding author, E-mail: takahiro.chujo@gmail.com ${ }^{2}$ Graduate Student, Department of Architecture and Architectural Engineering, Kyoto University, Kyoto, Japan.

${ }^{3}$ Assistant Professor, Department of Architecture and Architectural Engineering, Kyoto University, Kyoto, Japan.

${ }^{4}$ Professor, College of Science and Technology, Nihon University, Tokyo, Japan.

${ }^{5}$ Professor, Department of Architecture and Architectural Engineering, Kyoto University, Kyoto, Japan.
}

cities located in seismic regions of many countries; improvements in structural design are in demand.

A 14-story RC residential building Nuevo León, located in Nonoalco Tlatelolco apartment complex, is known to have suffered the most severe damage in Mexico City in 1985. It is supposed that the initial natural period of the Nuevo León building was approximately 1.0 second, but the period was elongated up to 2.0 seconds during the vibration due to structural damage including cracking, crushing, and bar yielding, and resonance with the ground motion occurred. The building consisted of three structurally independent units that were connected with non-structural expansion joints. After the earthquake, these joints had been destroyed, so it was supposed that pounding between the units occurred and significant impact load was applied to the building structure.

According to the reconnaissance by Bertero (1986), the pounding occurred in over $40 \%$ of the collapsed or severely damaged buildings and in at least $15 \%$ pounding was the primary cause of collapse. Several field researches on the pounding have also been conducted in Loma Prieta earthquake in 1989 (Kasai and Maison 1997), Darfield earthquake in 2010 (Cole et al. 2010) and Christchurch earthquake in 2011 (Cole et al. 2014). Comprehensive investigations in these researches indicate that many structural and non-structural failures were caused by the pounding although most of 
the observed buildings were lower than ten stories. In this regard, 1985 Mexico Earthquake is a unique case where middle to high-rise engineered buildings were subjected to the structural pounding.

The observed pounding indicated that the elongated natural period was unequal in each building unit due to unequal levels of damage. The disaster of the Nuevo León building provided a lesson that structural design must not only consider the initial natural period but also any elongated natural period during seismic vibration and the pounding of adjacent building structures due to changed and varied natural periods.

To date, several studies on the elongation of the natural period of RC buildings have been conducted. Masi and Vona (2010) conducted a shake-table test of a one-fourth scale four-story RC frame. The initial natural period of the frame was 0.48 second and elongated up to 0.83 second after the shaking. Ghannoum et al. (2012a, 2012b) designed a one-third scale three-story RC frame based on an old US code. The natural period before the shake-table test was 0.30 second. The frame was subjected to severe drifts larger than 3\% during the shaking and the natural period was elongated by up to 0.93 second. Kumazawa et al (2013) measured the natural period of 30-story RC building by micro-tremor devices before and after the Tohoku earthquake of March 11, 2011. The first-mode natural period measured in 2010 was 1.63 second. It was elongated to 1.96 second in 2012. Kumazawa also pointed out that period-elongation was caused not only by the earthquake but also by the aged degradation of concrete materials. Nagae et al. (2015) conducted a 3D shake-table test of a full-scale four-story RC frame with shear walls, which satisfied the US's and Japan's newest design codes. The initial natural period along the shear wall direction was 0.31 second and that along the frame without the wall was 0.44 second. After the shaking, these periods were elongated to 0.88 second and 0.99 second, respectively.

Influences of the impact load have been investigated by experimental and numerical means. Saatci and Vecchio (Saatci et al. 2009) conducted drop-weight tests of four RC beam specimens and precisely predicted their behaviors by the $2 \mathrm{D}$ finite element method. Fujikake et al. (2006) also conducted drop-weight tests and analyzed the structural behavior considering the local contact behavior. Burrell et al. (2015) studied the performances of eight RC column specimens subjected to blast loads and large plastic deformations. Kim et al. (2015) conducted drop-weight tests of 14 beam specimens considering a progressive collapse condition of RC buildings. Experimental and analytical studies of progressive collapse have been conducted by many researchers (Dat et al. 2015; Liu et al. 2015a, 2015b; Prasad et al. 2014; Qian et al. 2015a, 2015b). Among these, Liu et al. (2015a) analyzed the progressive collapse of a four-story RC building considering separation between columns and slabs due to punching shear. Fine 3D numerical models of a large number of degrees of
Table 1 Material properties.

\begin{tabular}{|c|c|c|}
\hline $\begin{array}{c}\text { Compressive concrete strength } \\
\text { (Column and wall) }\end{array}$ & $1-6 \mathrm{~F}$ & $27.4 \mathrm{~N} / \mathrm{mm}^{2}$ \\
\cline { 2 - 3 } & $7-14 \mathrm{~F}$ & $20.6 \mathrm{~N} / \mathrm{mm}^{2}$ \\
\hline $\begin{array}{c}\text { Compressive concrete strength } \\
\text { (Slab) }\end{array}$ & $1-3 \mathrm{~F}$ & $27.4 \mathrm{~N} / \mathrm{mm}^{2}$ \\
\cline { 2 - 3 } & $4-14 \mathrm{~F}$ & $20.6 \mathrm{~N} / \mathrm{mm}^{2}$ \\
\hline \multirow{2}{*}{ Yield strength of steel bar } & $\begin{array}{c}\text { Longitudinal } \\
\text { bar }\end{array}$ & $392 \mathrm{~N} / \mathrm{mm}^{2}$ \\
\cline { 2 - 3 } & Hoop & $230 \mathrm{~N} / \mathrm{mm}^{2}$ \\
\hline
\end{tabular}

freedom have also been used to estimate impact loads due to tsunami waves (Salem et al. 2014) and traffic accidents (Yi et al. 2015). Seismic poundings of adjacent buildings have been conducted by scaled model tests (Goland 1955; van Mier et al. 1991; Zhu et al 2002; Jankowski 2010) and analytical methods (Anagnostopoulos et al. 1992; Maison et al. 1992; Davis 1992; Jankowski 2005; Jankowski 2006; Anagnostopoulos et al. 2008; Isobe et al. 2012). Jankowski conducted a finite element analysis of (Jankowski 2009) the pounding behavior between main building and stairway tower of Olive View Hospital damaged in San Fernando earthquake in 1971. The analysis result indicates that the smaller stairway tower is significantly influenced by the pounding while the larger main building is slightly influenced. Isobe et al. (2012) successfully simulated the pounding and collapse behaviors of the Nuevo León building using a large 3D numerical mode, although the change of natural period during the vibration is not computed.

To investigate the behavior of the Nuevo León building, however, several phenomena including elongation of natural period, resonance with ground motion, and pounding between adjacent buildings accompanied with transverse friction must be simultaneously considered. It is worth mentioning that the friction is supposed at the instance of pounding especially in Nuevo León, where the transverse (east-west) vibration amplitude was larger than the longitudinal (north-south). This study attempts to quantitate the period-elongation and the impact load due to contact/friction by means of finite element analyses and experimental tests of $\mathrm{RC}$ column specimens. Based on these quantifications, a constitutive model of the local contacting behavior is proposed and a finite element analysis of two adjacent building units is conducted.

\section{Preliminary analyses of entire building}

\subsection{Building structure and two finite element models}

Nuevo León had a 14-story RC structure with a waffle slab system. The building of $159.5 \mathrm{~m}$ long in the north-south direction consisted of three units each 53.1 $\mathrm{m}$ long connected with $100 \mathrm{~mm}$-wide expansion joints. Figure 1(a) shows the west exterior elevation and Fig. 1(b) a typical floor plan. Table 1 lists the strengths of the materials used in the building. It has been pointed 
Table 2 Configurations of finite element models of building.

\begin{tabular}{|c|c|c|c|c|c|c|c|}
\hline \multirow{2}{*}{ Model } & \multirow{2}{*}{ Number of nodes } & \multicolumn{5}{|c|}{ Number of elements } & \multirow{2}{*}{ Total degrees of freedom } \\
\cline { 3 - 7 } & & Hexahedral & Quadrilateral & Beam & Four-node joint & Two-node joint & \\
\hline Basic & 19,648 & 2,304 & 8,620 & 5,126 & 1,698 & 0 & 101,912 \\
\hline Jointed & 19,718 & 2,304 & 8,620 & 5,126 & 1,698 & 70 & 101,912 \\
\hline Two-unit & 23,256 & 3,728 & 9,540 & 4,950 & 818 & 70 & 116,661 \\
\hline
\end{tabular}

out that the collapse of Nuevo León was caused by at least two phenomena: (1) the resonance between a relatively long predominant period of ground motion and the natural period of the damaged building, and (2) the impact load due to the pounding at the expansion joints between the adjacent units. In this section, two preliminary analyses are conducted using two finite element models of a single building unit. The first model (basic model; Fig. 2(a)) is used to estimate the change of natural period of the Nuevo León due to seismic damage and simulate the resonance with the ground motion. The second model (jointed model; Fig. 2(b)), which consists of joint elements on one of lateral sides of the building, is used to judge the occurrence of contact between the building units and roughly evaluate the lateral reaction. The finite element analysis program used is FINAL (Naganuma et al. 2004).

The two finite element models shown in Figs. 2(a) and (b) represent the northern unit of the Nuevo León building (Fig. 1). The unit is $53.1 \mathrm{~m}$ long in the north-south direction and $12.5 \mathrm{~m}$ wide in the east-west direction. Figure 2(c) shows details of the mesh division of the columns and slabs. Fine meshes are provided for the lower stories while coarse meshes are used in the upper stories to reduce the amount of computations. The first story exterior columns are modeled by eight-node hexahedral elements with the finest mesh division (indicated by circles in Fig. 1(b)) since large axial and shear forces are expected. The other columns in the first story and those in the second story are modeled by four-node quadrilateral elements, and those in the third story and above by two-node beam elements. Apart from the concrete, longitudinal steel bars in the columns are modeled by the two-node beam elements. The bonds between the bars and the concrete are modeled by the four-node joint elements. The waffle slab system is modeled by four-node quadrilateral elements with the equivalent out-of-plane bending stiffness and yield strength. Based on the reconnaissance report (AIJ 1987), weight per a unit floor area $0.999 \mathrm{ton} / \mathrm{m}^{2}$ is assumed. In this assumption, the total mass of the building becomes 9,868 tons. Table 2 shows the model configurations.

For the jointed model shown in Fig. 2(b), a rigid reaction plane is placed on the southern side (i.e., right side in Fig. 2(b)) of the building and the two-node joint elements are inserted to roughly simulate the lateral reaction due to contact between adjacent units. The element to model the colliding behavior is classified into three kinds: linear viscoelastic model (Anagnostopoulos 1992; Jankowski 1998, Anagnostopoulos 1998, Valles and Reinhorn 1997), nonlinear elastic model (Jing and Young 1991; Pantelides and Ma 1998; Chau and Wei 2001; Goldsmith 1960), and nonlinear viscoelastic model (Jankowski 2005, 2006). It has been pointed out that the linear viscoelastic model, which assumes the same damping coefficient during the whole time of collision, is not fully consistent with the reality comparing the latter two models (Goldsmith 1960; Valles and Reinhorn 1997). Nevertheless, the former is significantly beneficial in the interest of simple implementation to the finite element analysis. The analyses in this study therefore adopt the linear viscoelastic model.

The reaction plane is placed $50 \mathrm{~mm}$ from one side of the building and connected with the node of the top of

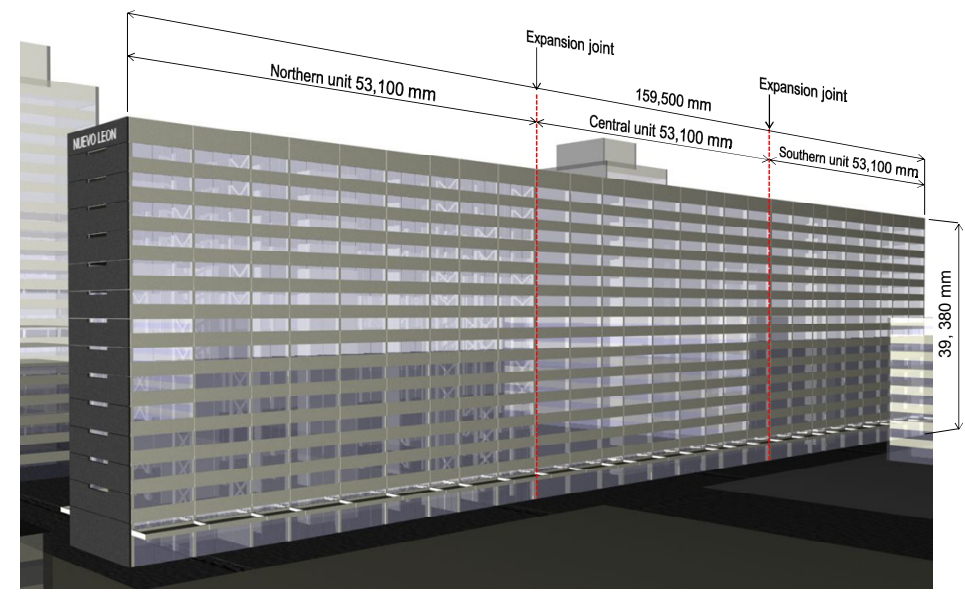

(a) West exterior elevation

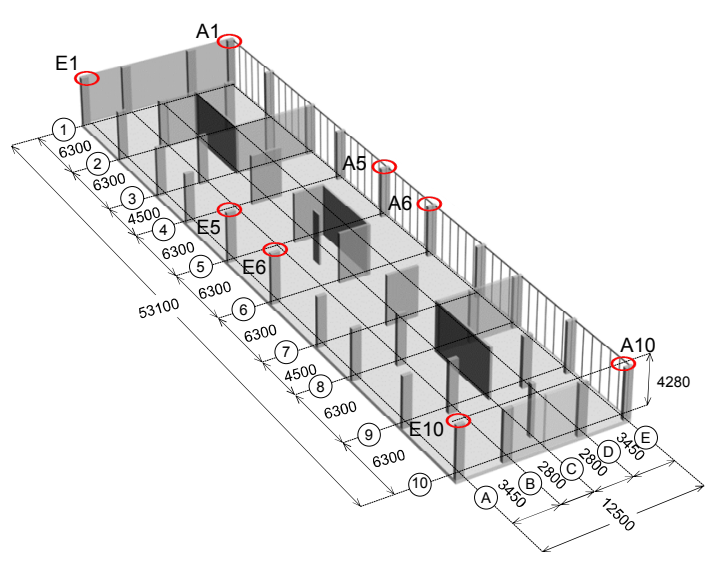

(b) First story plan of northern unit

Fig. 1 Exterior and plan of Nuevo León building. 
each column by the two-node joint elements. The 50 $\mathrm{mm}$ spacing is determined as half of the $100 \mathrm{~mm}$-wide expansion joints. Figure 2(b) exaggerates the separation between the reaction plane and the building in the interest of easier recognition. Figure 3 shows the stress-displacement relationship model implemented for the two-node joint elements. The lateral axis represents the relative displacement between the reaction plane and the building side. Compressive stress is induced if the displacement reaches $-50 \mathrm{~mm}$. This means the contact between the adjacent building units. The maximum compressive stress is limited within the compressive strength of the concrete to allow local plastic deformation. The positive displacement means the separation of the buildings, so no stress is induced. However, only $0.001 \mathrm{~N} / \mathrm{mm}^{2}$ is induced to maintain numerical stability. No resistance is assumed along the direction parallel to the reaction plane.

Table 3 lists the constitutive models (Naganuma et al. 2004; Sato et al. 2007, 2014; Ciampi et al. 1982; fib 2010). Figure 4 shows the first, second and third natural vibration mode shapes computed using the subspace iteration method. The first mode includes the transverse
Table3 Constitutive models.

\begin{tabular}{|l|l|}
\hline $\begin{array}{l}\text { Compression base curve; } \\
\text { Compression softening; Ten- } \\
\text { sion stiffening; Cracking crite- } \\
\text { rion; Shear transfer character- } \\
\text { istic; Non-linear Poisson effect }\end{array}$ & Naganuma 2004 \\
\hline Crack spacing & $\begin{array}{l}\text { Sato and Naganuma 2007, } \\
2014\end{array}$ \\
\hline Strain hardening & Kinematic hardening law \\
\hline Steel hysteresis & Ciampi, V. et al. 1982 \\
\hline Steel bond stress & fib Model code 2010 \\
\hline Bond stress - Slip curve & $\begin{array}{l}\text { Naganuma 2004 and fib } \\
\text { Model code 2010 }\end{array}$ \\
\hline
\end{tabular}

deformation while the second and third the longitudinal and torsional deformations. The natural periods for the model have been determined as equal to: $\mathrm{T}_{1}=1.14 \mathrm{sec}$. and $\mathrm{T}_{2}=0.95 \mathrm{sec}$. and $\mathrm{T}_{3}=0.94 \mathrm{sec}$., respectively.

The seismic acceleration measured by Mexico's Secretary of Communications and Transportations (SCT1) (AIJ 1987) is directly input to the model (Fig. 5). Figure 6 shows the spectrum of input acceleration. The total number of calculation steps is 6011. Dead load is

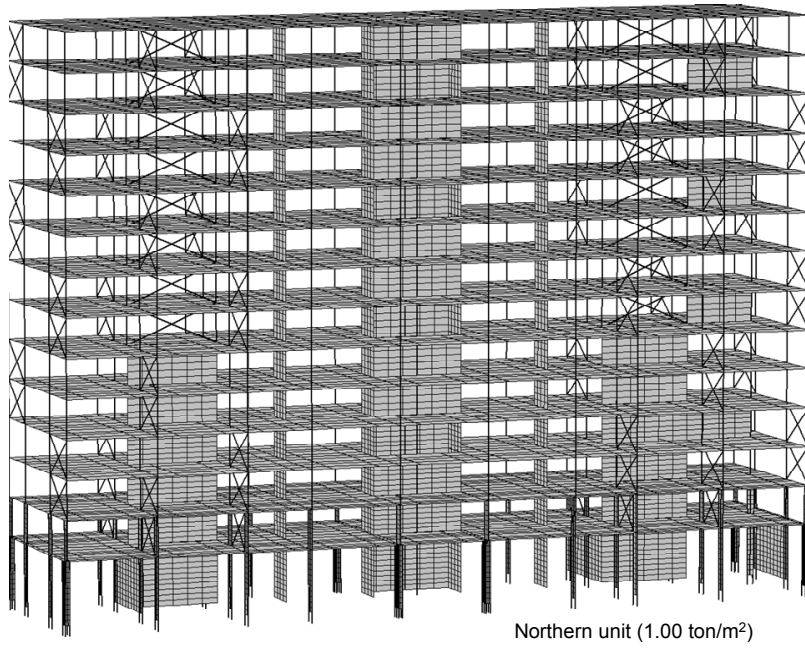

(a) Basic model

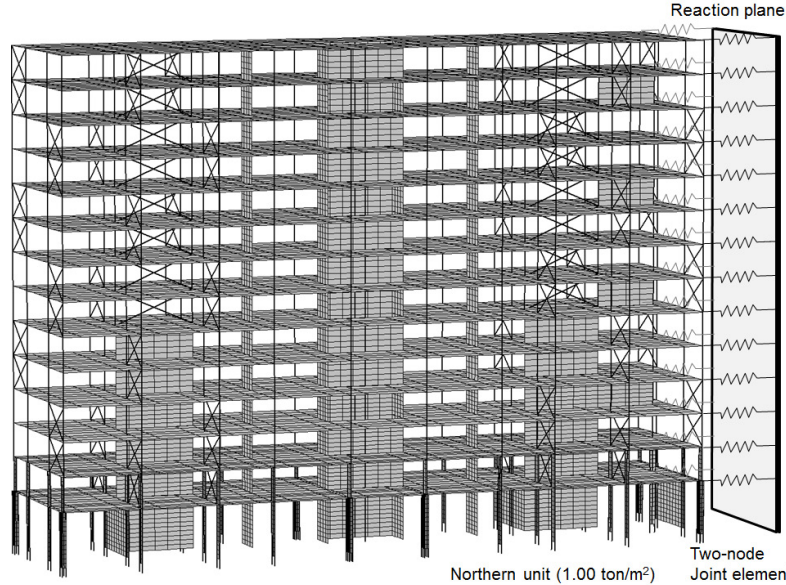

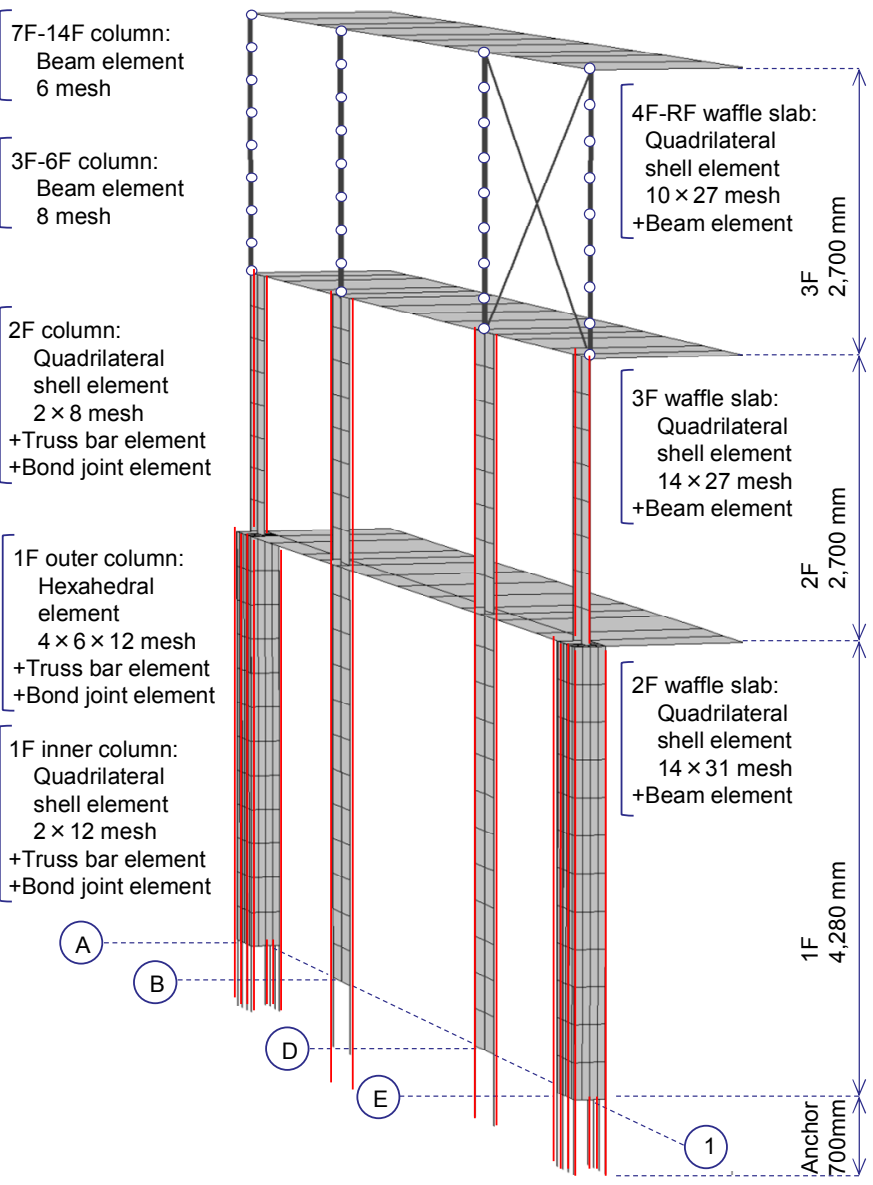

(c) Detail of mesh division

(b) Jointed model

Fig. 2 Preliminary analysis models. 
applied at the initial 11 steps and the $\mathrm{x}, \mathrm{y}$, and $\mathrm{z}$ components of SCT1 acceleration are applied at the following 6000 steps with a time increment of 0.01 second per step. The Newmark- $\beta$ time integration method was adopted with parameters $\beta=0.25$ and $\gamma=0.5$ with uniform $1 \%$ damping assumed for the first natural period. The total computation time depends on the hardware, but approximately one week is needed by an ordinary personal computer sold in the 2010 s.

\subsection{Analyses results}

Figure 7 shows the relationships between total deformation ratio and time. Total deformation ratio is defined as the ratio of displacements at the top of the building to the building height, $39,380 \mathrm{~mm}$. The total deformation ratio is classified into the north-south, east-west, and

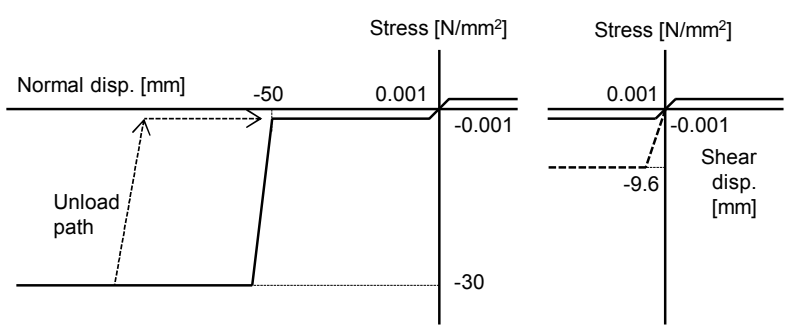

Fig. 3 Constitutive model for two-node joint element of jointed model.

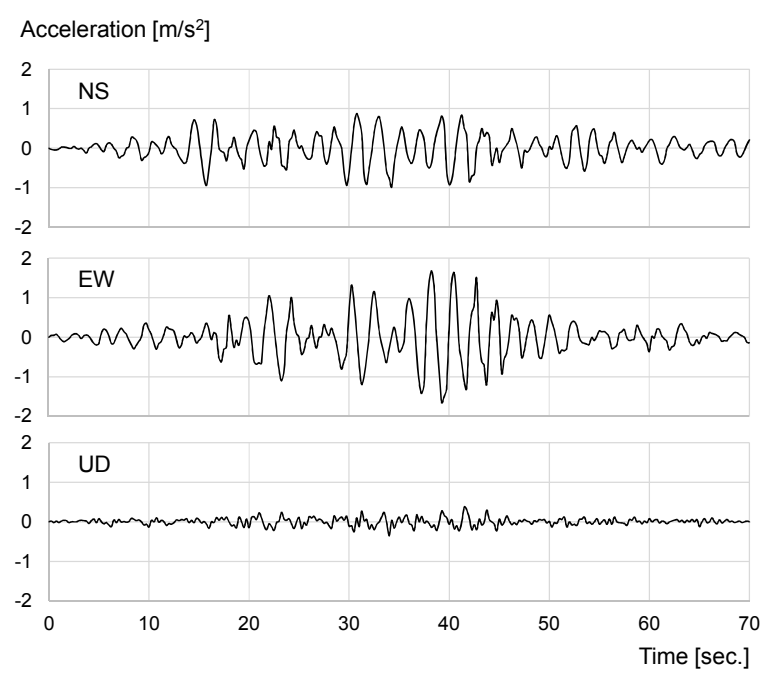

Fig. 5 Input acceleration SCT1.

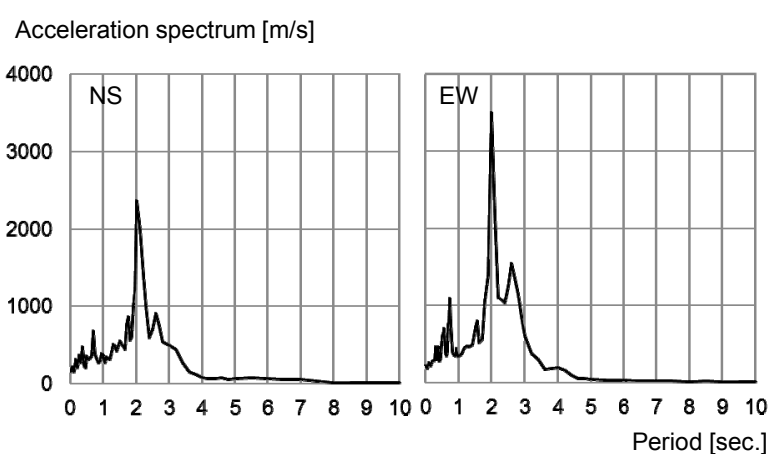

Fig. 6 Input acceleration spectrum. up-down components. As Fig. 7 indicates, the total deformation ratio in the east-west direction is larger than that in the north-south direction. This corresponds to the fact that the east-west component of the input acceleration is larger than that of the north-south component.

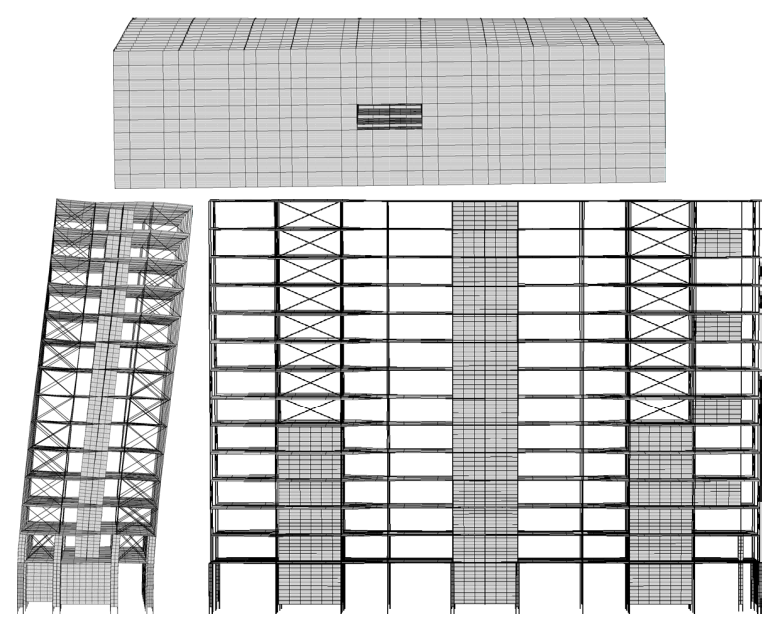

(a) First mode $\left(\mathrm{T}_{1}=1.14 \mathrm{sec}\right.$. $)$
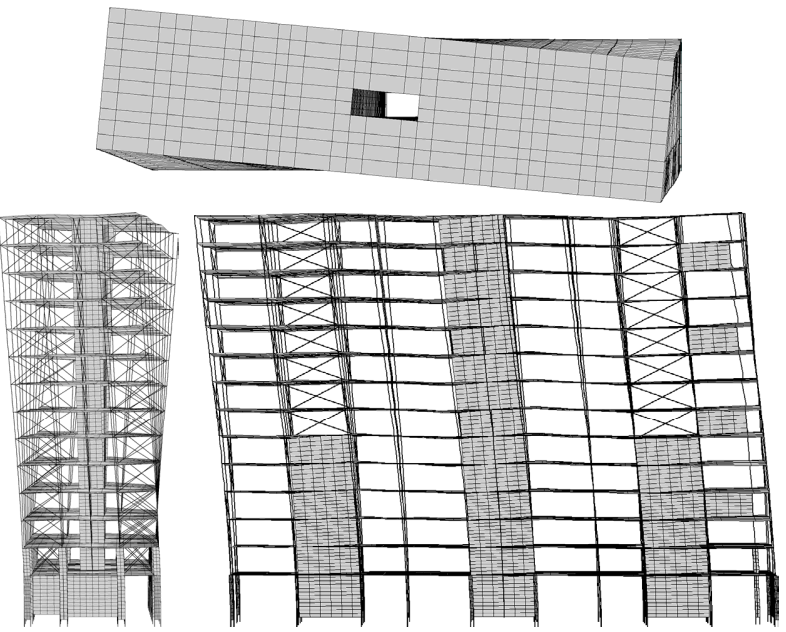

(b) Second mode $\left(\mathrm{T}_{2}=0.95 \mathrm{sec}\right.$. $)$
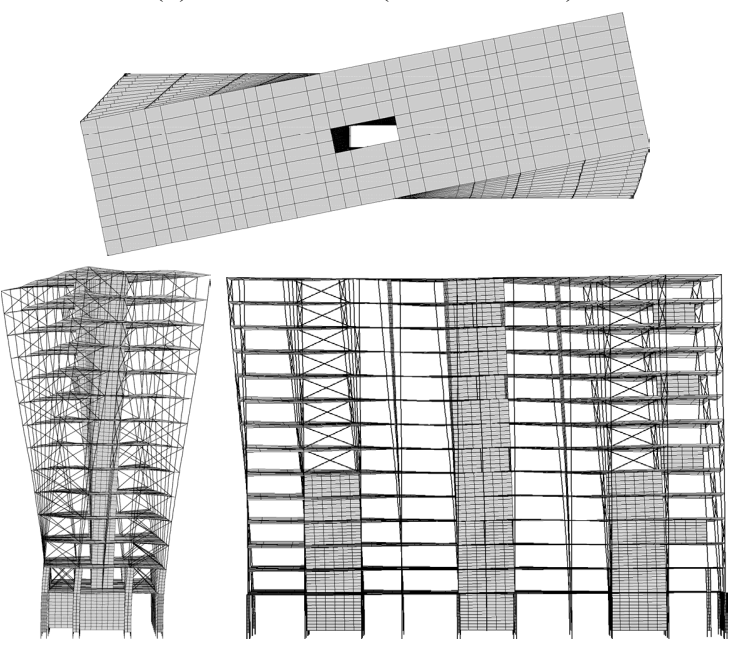

(c) Third mode $\left(\mathrm{T}_{3}=0.94 \mathrm{sec}\right.$. $)$

Fig. 4 First, second and third natural vibration modes for basic model. 


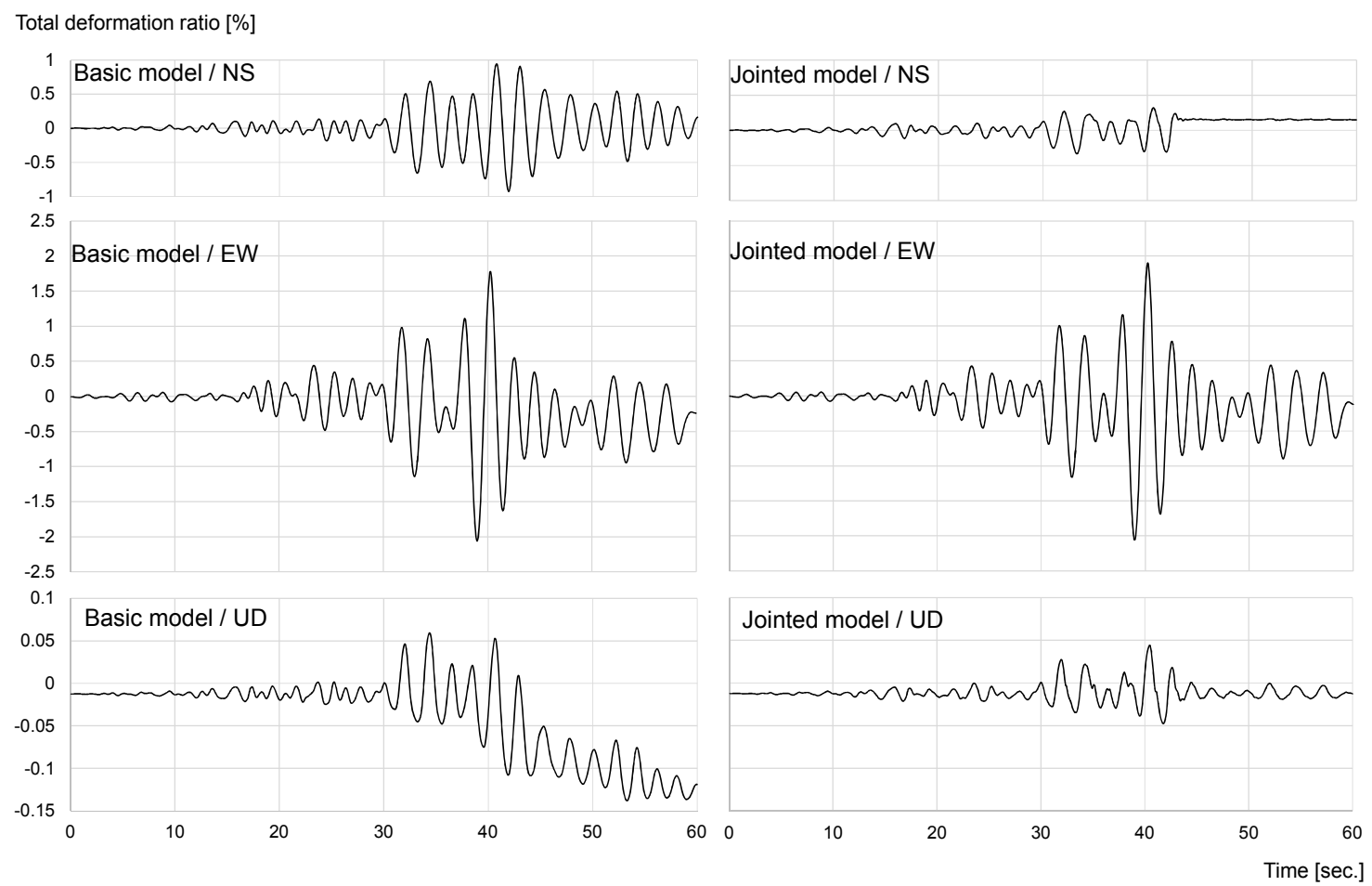

Fig. 7 Relationships between total deformation ratio and time.

The maximum and minimum total deformation ratios are observed at around 40 seconds in both directions. After 40 seconds, the center of the amplitude of the east-west vibration is slightly biased to the west (i.e., negative) side. It is supposed that the two shear walls in the first story located in $3 \mathrm{~A}-3 \mathrm{C}$ and $8 \mathrm{~A}-8 \mathrm{C}$ axes increase axial stiffness of the east side whereas they reduce that of the west side and result in unbalanced deformation.

The response in the east-west direction of the jointed model is similar to that of the basic model. In contrast, the total deformation ratio in the north-south direction of the jointed model is considerably reduced because of the reaction of the joint elements applied on the southern side. The maximum deformation ratio exceeds $0.13 \%=$ $50 \mathrm{~mm} / 39,380 \mathrm{~mm}$ in southern (negative) direction, where the reaction wall is placed, because the joint element allows the plastic deformation over this displacement. The deformation becomes almost zero after 43 seconds. The up-down displacement of the jointed model is also reduced. It is supposed that the smaller north-south displacement reduces the damage of the columns and therefore reduces the axial deformations.

Figure 8 shows the relationship between the natural period and time of the basic model computed using the tangent stiffness of each finite element. The initial natural period of the basic model is 1.2 second. The natural period is gradually elongated over time because the stiffness of the structure is reduced by cracking, crushing, shear failure, and bar yielding. The maximum natural period of 2.5 seconds was recorded at time 52 seconds. The zig-zag profile observed after 43 seconds was caused by the varied stiffness of the hysteresis paths in the materials' stress-strain relationships. The natural

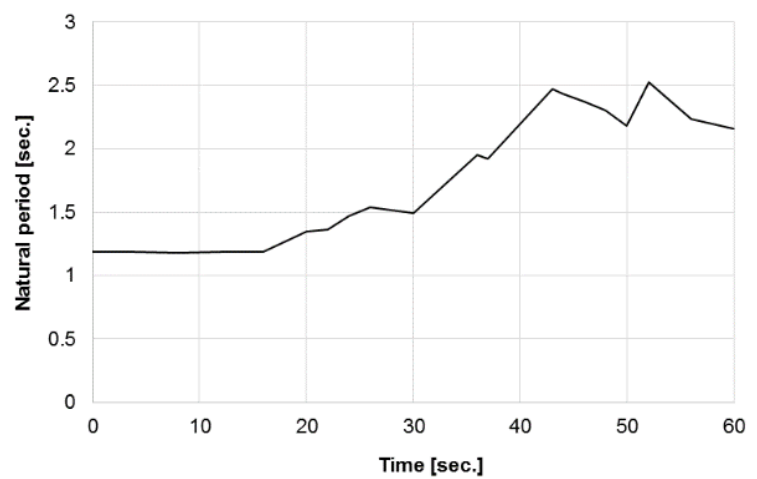

Fig. 8 Relationship between natural period and time of basic model.

period of the same type of buildings that survived the earthquake, measured by micro-tremor instruments, was 1.95 seconds. This observed value roughly agrees with the computed value.

Figure 9 shows the relationships between the total load applied to the building and the total deformation ratio. The vertical axis represents the ratio of the total horizontal load to the total building mass, 9,868 tons. A significant difference is found in the north-south direction between the two models. The maximum total load ratios of the basic and jointed models are 0.012 and 0.078 , respectively. Hence, the load is increased by 6.5 times by reactions of the joint elements. The total load in the east-west direction of the jointed model is also increased although not as significantly as that of the north-south direction.

Figure 10 shows the relationships between stress and 
displacement of the joint elements of the top story of the jointed model. The compressive stresses are induced as the negative displacement exceeds $-50 \mathrm{~mm}$. These compressive stresses correspond to the reaction force in the north-south direction, shown in Fig. 9.

Analysis of the basic model indicates that the natural period of the Nuevo León is almost doubled during the seismic vibration and resonance with the ground motion. The analysis result of the jointed model indicates that a considerably large impact load is induced due to contact between the adjacent building units. However, the impact load evaluated in this section is derived from a rough model using the joint elements and the reaction plane. Therefore, the local contact and friction behav- iors of two columns are experimentally investigated in the next section.

\section{Tests and finite element analyses of RC columns subjected to contact/friction}

\subsection{Test plan and result}

Repeated cyclic loads are applied to two RC column specimens to observe the influence of the pounding accompanied with the friction and to obtain basic data to model contact/friction behavior in the FE analysis. According to the field investigation report, the geometry and material properties of the specimens represent the columns at the seventh floor of northern unit of the
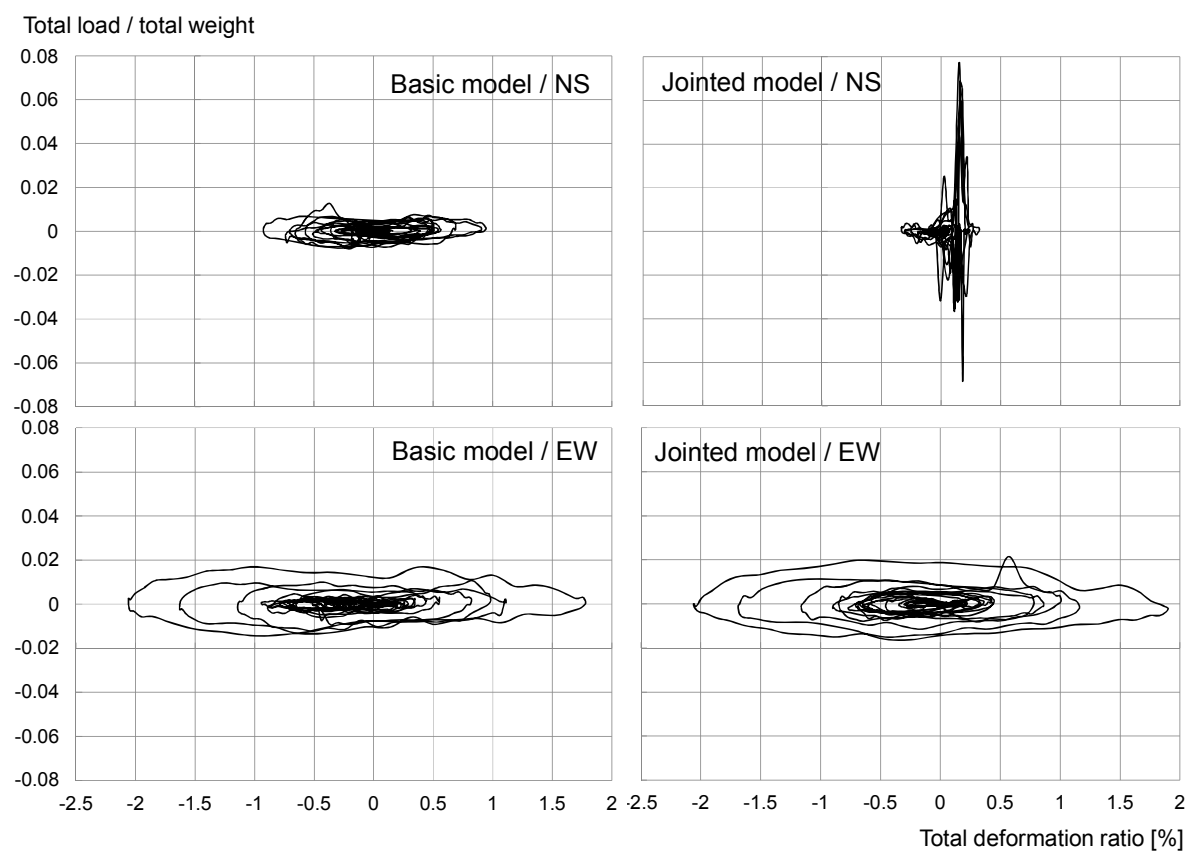

Fig. 9 Relationships between total load and total deformation ratio.
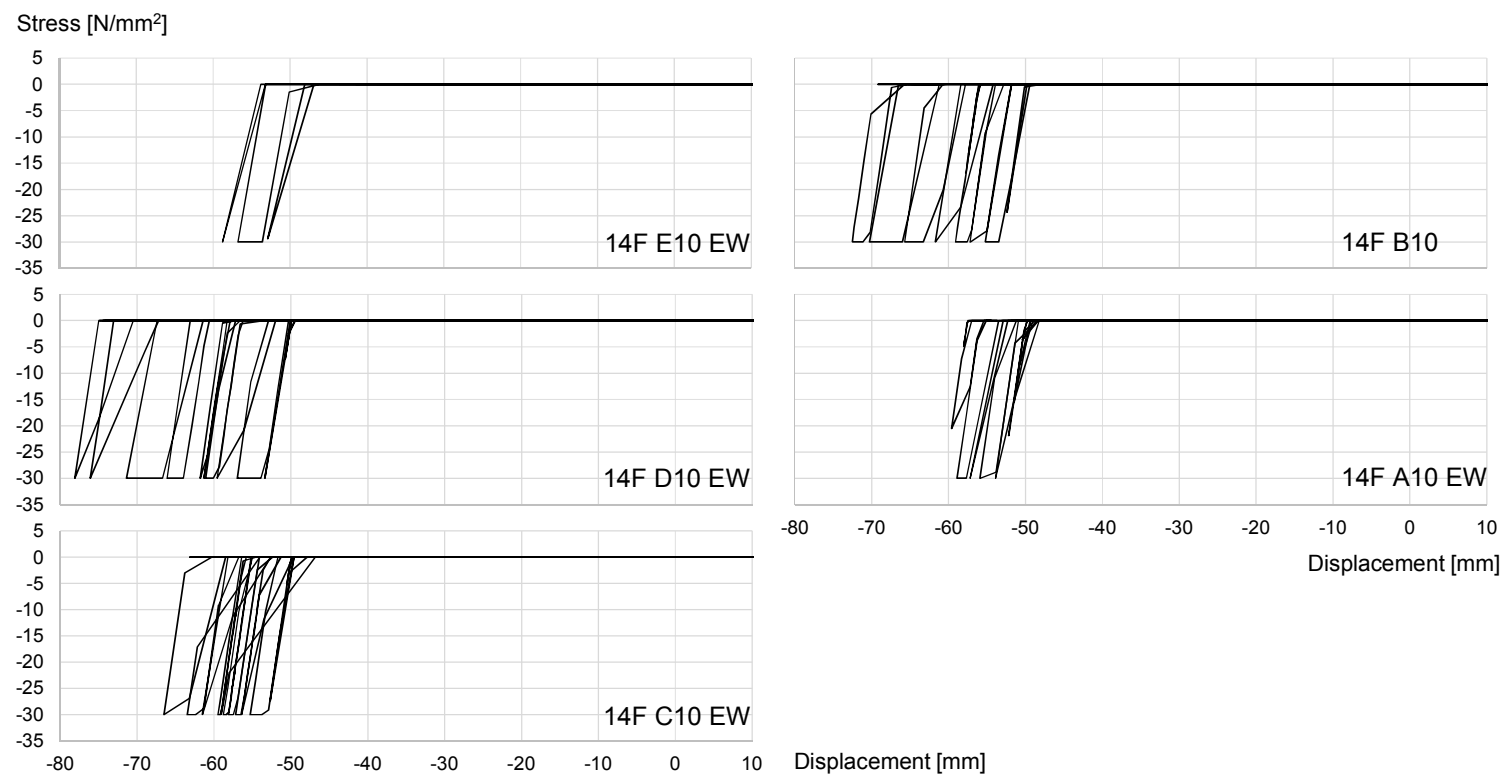

Fig. 10 Relationships between stress and displacement of two-node joint elements of jointed model. 
Table 4 Configurations and test results of Specimens NL1 and NL2.

\begin{tabular}{|c|c|c|c|c|}
\hline Specimen & Pounding block & Axial force kN & Calculated flexural strength kN & Max shear force in test kN \\
\hline NL1 & No presence & 432 & 201 & 175.4 \\
\hline NL2 & Presence & 432 & 201 & 227.6 \\
\hline
\end{tabular}

Nuevo León (AIJ 1987). Figure 11 shows the geometry of the specimens and Table 4 summarizes the specifications. Each specimen was $2,400 \mathrm{~mm}$ in clear span and $250 \mathrm{~mm}$ by $400 \mathrm{~mm}$ in cross-section. Four pairs of two bundled longitudinal bars of $19 \mathrm{~mm}$ in diameter are arranged. In the actual column, shear reinforcing bars of $10 \mathrm{~mm}$ in diameter are arranged in $200 \mathrm{~mm}$ spacing. However, it is of concern that the small amount of shear reinforcement in the actual column may make the specimens too week to observe the pounding behavior. Therefore, the spacing is reduced to $100 \mathrm{~mm}$ so that the amount is doubled. The compressive strength of concrete is $28.8 \mathrm{~N} / \mathrm{mm}^{2}$ and the axial force ratio is 0.15 . Specimens were located vertically and positive and negative antisymmetric loads were applied. Positive and negative rotation angles of $0.125 \%, 0.25 \%, 0.5 \%, 1 \%, 1.5 \%, 2 \%, 3 \%, 4 \%$, and 5\% were each applied twice. Figure 12 shows the specimens mounted in the test apparatus.

Specimen NL1 is an ordinary column of 2,400 mm span while Specimen NL2 has four "pounding blocks" of 1,200 mm length. Two of the blocks (upper pounding blocks) are connected at the top fixing block while the other two (lower pounding blocks) are connected to the bottom fixing block. One of two upper pounding blocks and one of two lower pounding blocks contact the main column when a positive shear load is applied, whereas the other upper and lower blocks contact when a negative load is applied. The facing surfaces of the pounding block and the main column are angled by $1: 2$ (i.e., 26.6 degrees). This angle is determined based on the ratio of maximum deformation angles in the NS direction $(1 \%)$ and the EW direction $(2 \%)$. The main column and the pounding blocks are separated by 2 $\mathrm{mm}$ spacing to induce contact/friction on the halfway point of the hysteresis curve so that any change in stiffness can be easily detected.

The maximum shear force induced in Specimen NL2 is larger than that of NL1 because of the friction of these contacts. No decrease in shear force is observed until the rotation angle (= horizontal displacement / span) reaches $5 \%$.

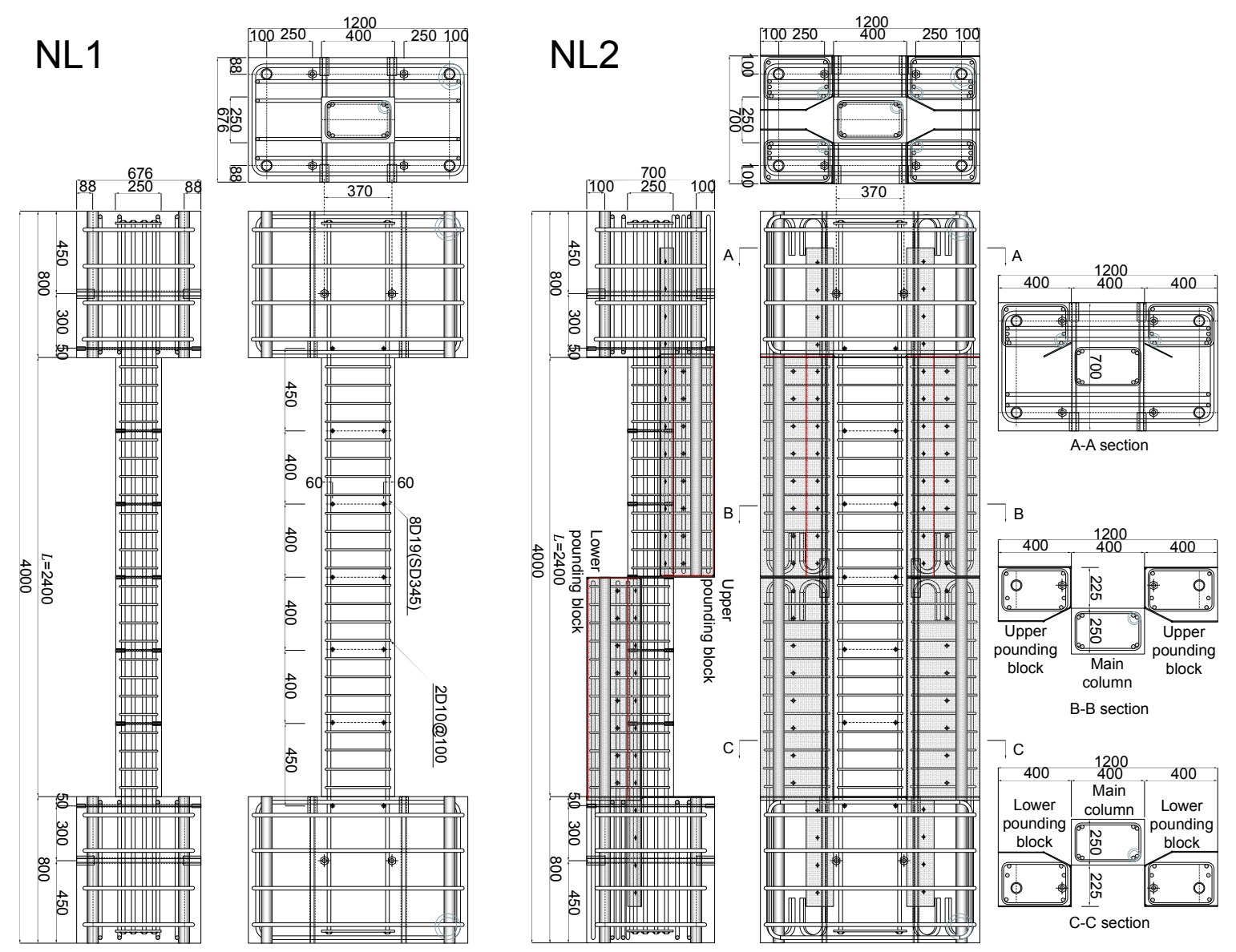

Fig. 11 Specimen configurations. 
Figure 13 shows the relationships between shear force and rotation angle. Specimen NL1 had a stable hysteresis curve retaining at $170 \mathrm{kN}$ after the longitudinal bars yield at a rotation angle $0.7 \%$. In Specimen NL2, shear force gradually increases as the rotation angle increases after the longitudinal bars yield and attains the maximum shear force at $228 \mathrm{kN}$. The maximum shear force of specimen NL2 is therefore larger than that of Specimen NL1 by $30 \%$ due to the resistance between the main column and the pounding blocks. Before the yielding of longitudinal bars, the resistance is insignificant. After the bars yield and the rotation angle exceeds $1.0 \%$, the main column and the pounding blocks contact and hardening is observed on the hysteresis curve. This change of gradient of the hysteresis curve occurs at a shear force of $160 \mathrm{kN}$, as shown in Fig. 13. The peak shear force reaches $200 \mathrm{kN}$ or larger. The contact and friction between the main column and the pounding blocks are observed at every loading cycle. During the pounding, significant noises are heard. The main column immediately separates from the pounding blocks as unloading begins. The unloading part of the hysteresis curve of Specimen NL2 is similar to that of NL1. Specimen NL2 maintains a large shear force until the last loading cycle (i.e., rotation angle $=5 \%$ ) and presents no premature failure as was of concern when the specimens were designed.

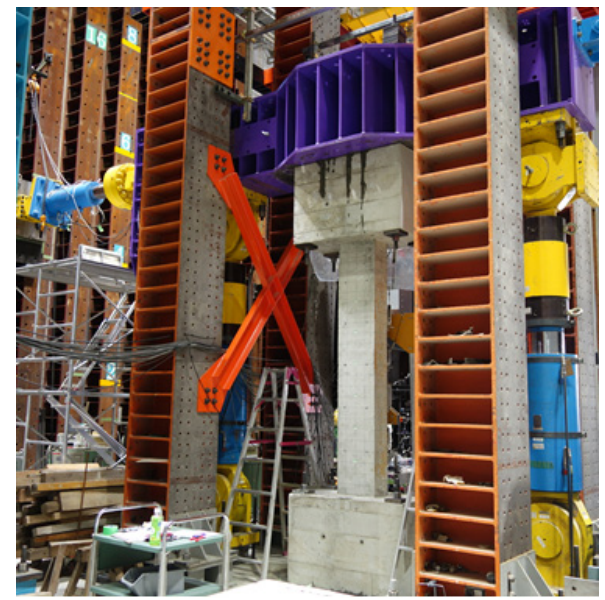

(a) Loading apparatuses

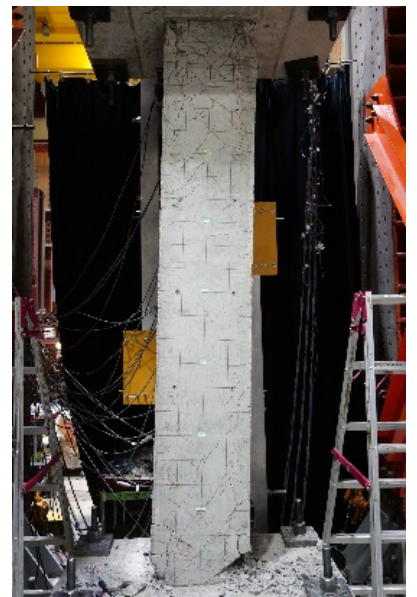

(b) Final condition of NL1

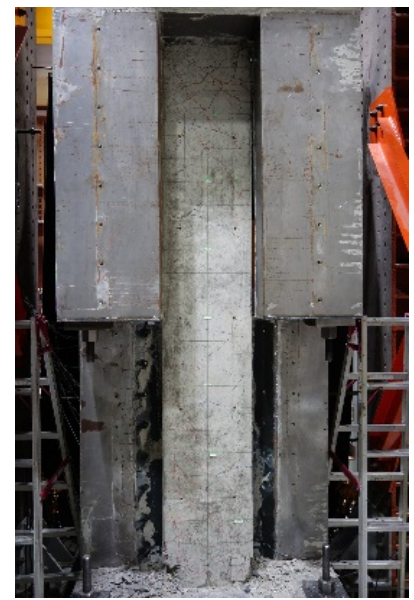

(c) Final condition of NL2

Fig. 12 Loading tests.

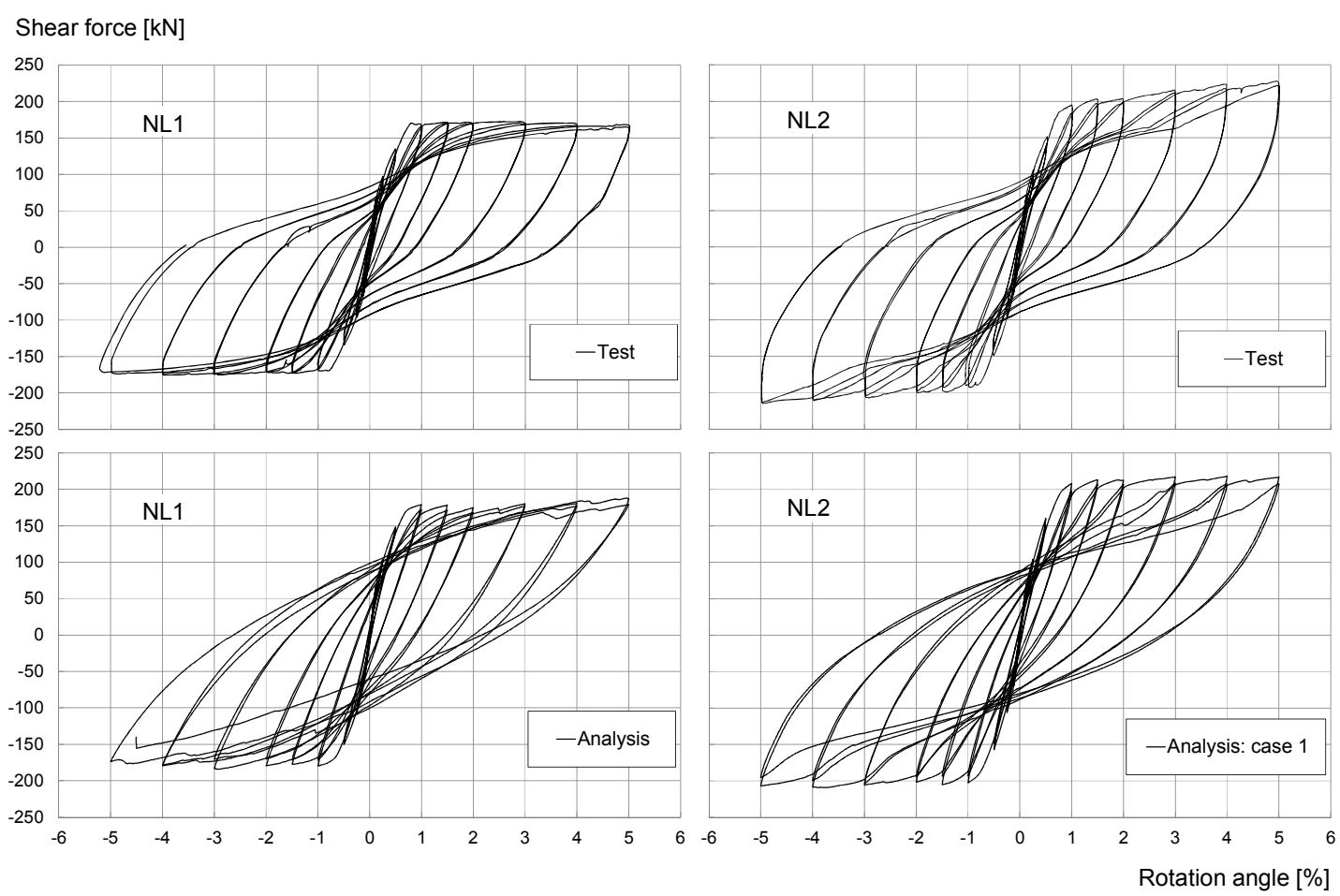

Fig. 13 Relationships between shear force and rotation angle. 
Table5 Configurations of finite element modeling of Specimens NL1 and NL2.

\begin{tabular}{|c|c|c|c|c|c|c|c|}
\hline \multirow{2}{*}{ Specimen } & \multirow{2}{*}{ Number of nodes } & \multicolumn{4}{|c|}{ Number of elements } & \multirow{2}{*}{ Total degrees of freedom } & \multirow{2}{*}{ Total analysis steps } \\
\cline { 3 - 6 } & & Hexahedral & Truss & Four-node joint & Two-node joint & & \\
\hline NL1 & 10,225 & 7872 & 240 & 240 & 0 & 28,895 & 13,346 \\
\hline NL2 & 16,369 & 12,912 & 960 & 240 & 184 & 47,327 & 13,346 \\
\hline
\end{tabular}

\subsection{Finite element modeling}

The behaviors of Specimens NL1 and NL2 are analyzed by the finite element method to quantify stresses induced in the contact/friction parts and develop a constitutive model of this local contact/friction behavior. A grid of $8 \times 8$ rectangular elements was used for the cross-section of two specimens. The 2,400 mm-high clear span is divided into 48 meshes, so the height of an element is $50 \mathrm{~mm}$ in the clear span. For the fixing part on both sides of the clear span, the height is divided into six meshes and the spacing is biased so that the spacing becomes wider towards the end side of the fixing bock. The concrete is modeled by an eight-node hexahedral element. The bundled longitudinal bars are used in the actual column as described above, but a pair of two bundled bars are modeled by a two-node truss element and placed at each corner of the rectangular cross-section. To model bond behavior, the truss elements are indirectly connected to the concrete elements with four-node joint elements. The bond model, which is based on Naganuma's study (Naganuma et al. 2004), is implemented into these four-node joint elements. Shear reinforcing hoops are modeled as embedded bars in the hexahedral elements. Figure 14(a) shows the finite element meshes and Table 5 shows the model configurations.

In the model of Specimen NL2, the main column and the pounding blocks are separated by $2-\mathrm{mm}$ spacing and connected with two-node joint elements, as shown in Fig. 15. Each two-node joint element consists of three orthogonal springs that represent normal and two shear (friction) components. For the normal component spring, zero stress is assumed in the tension side to model the
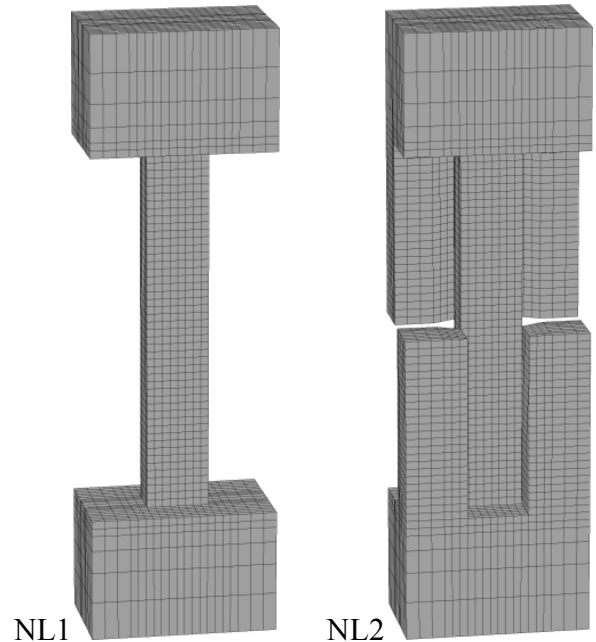

(a) Mesh divisions separation. To avoid numerical underflow problems, a bilinear consisting of an initial gradient of $0.001 \mathrm{~N} / \mathrm{mm}^{2}$ and a second plateau is adopted. A bilinear is also used in the compression side, but a negative stress equal to the compressive concrete strength $28.8 \mathrm{~N} / \mathrm{mm}^{2}$ is induced when the normal displacement exceeds $-5.0 \mathrm{~mm}$. The shear (friction) spring is inactive when no stress is induced to the normal spring, and becomes active when the compressive stress is induced to the normal spring. The maximum stress of the shear spring is one-third that of the normal spring, $9.6 \mathrm{~N} / \mathrm{mm}^{2}$. The gradient of the unload path is assumed to be equal to the initial stiffness. Parametric analyses are conducted by the stress-displacement relationships in both the normal and shear directions. Figure 16 shows three typical models. The first is a high stiffness type (Case 1) with bilinear

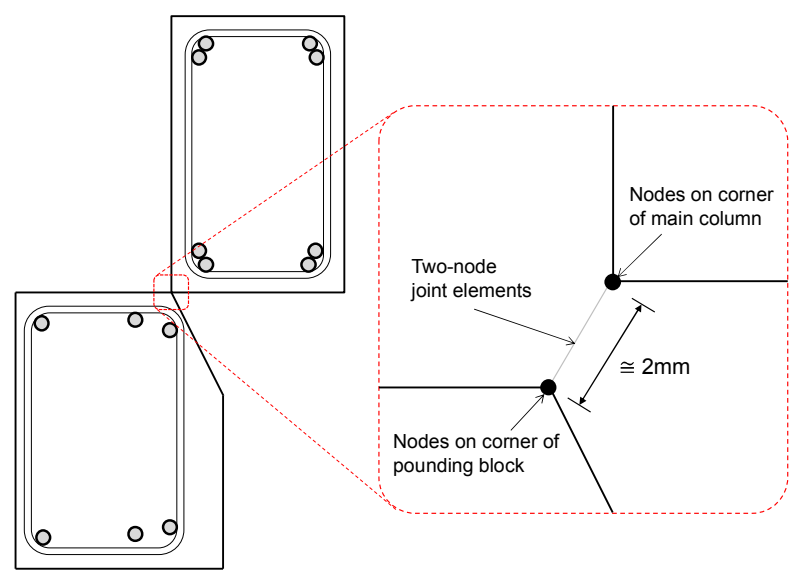

Fig. 15 Two-node joint element inserted between main column and pounding block of Specimen NL2.
NL1

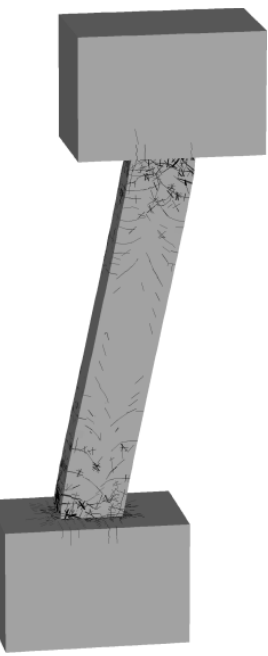

NL2

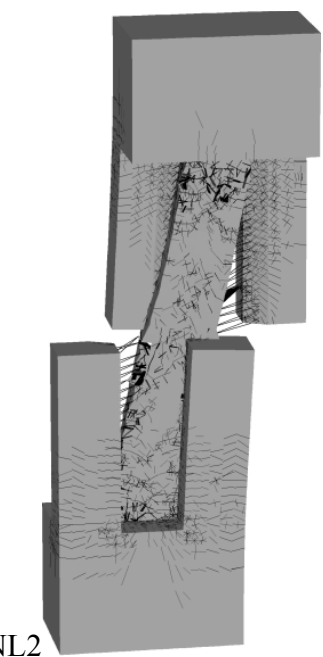

(b) Deformations and crack patterns (rotation angle $=3 \%$ )

Fig. 14 Analysis models of Specimens NL1 and NL2. 
branch displacement of $-5.0 \mathrm{~mm}$. The second (Case 2) is a medium stiffness type with $-50 \mathrm{~mm}$ displacement and the third (Case 3 ) is a low stiffness type with $-100 \mathrm{~mm}$ displacement.

Figure 13 shows analyzed relationships between shear force and rotation angle of Specimens NL1 and NL2 by the Case 1 joint model. Figure 14(b) shows deformations and crack patterns at a rotation angle of $3 \%$. The analysis results of the two specimens agree well with the test results with respect to initial stiffness, maximum load, and the entire hysteresis. The maximum load of Specimen NL2 in the analysis is slightly smaller than that in the test, but the difference does not exceed $5 \%$. The change of stiffness due to the contact/friction at a shear force of around $160 \mathrm{kN}$ is observed in the analysis of Specimen NL2. Figure 17
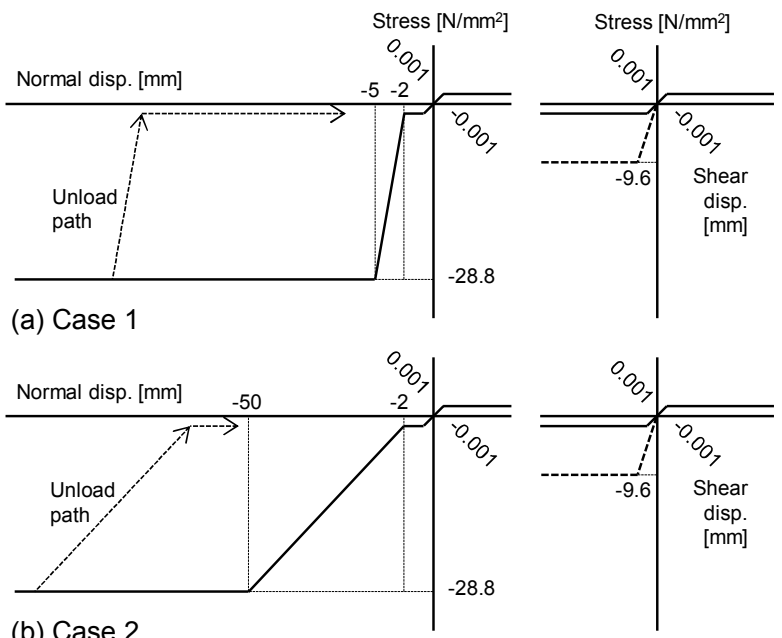

(b) Case 2
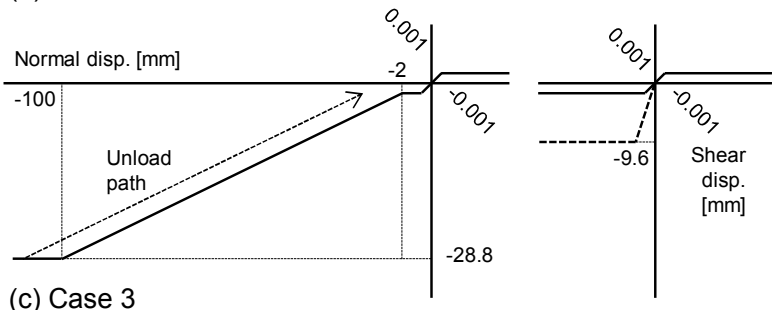

Fig. 16 Constitutive models of two-node joint element for Specimen NL2. shows the parametric analysis results of Specimen NL2 by the Cases 2 and 3 models. Figure 17 indicates that the maximum shear force decreases as the rotation angle increases if the medium and low stiffness joint models are used. Hence, the analysis in the following section adopts the high stiffness joint model shown in Fig. 16(a). Figure 18 shows two typical relationships between force acting on the pounding block and rotation angle derived from the test and the analysis using the Case 1 joint model. The test result is estimated using the measured strain gauge values. On the other hand, the analysis result, which is the computed distribution of the load indicated in the vertical axis, is given by obtaining the sum of stresses of the two-node joint elements aligned along 1,200 mm long pounding block divided by the contact area. The analysis result is in close agreement with the test.

\section{Time history response analysis of two adjacent building units}

In this section, a time history response analysis is conducted using a finite element model of the two building units shown in Fig. 19 (two-unit model). The model extracts the north and central units from the three units of the Nuevo León. Each unit is a partial model, which extracts six out of nine spans in the north-south direction (i.e., the fifth to tenth axes of the northern unit and the first to sixth axes of the central unit) to reduce the number of computations. In the single unit models used in the preliminary analyses, eight exterior columns only in the first story are modeled by the eight-node hexahedral elements. In contrast, the hexahedral elements with the finest mesh division are used for the four exterior columns in all 14 stories of the frames facing each other (i.e., A10 and E10 of the northern unit and A1 and E1 of the central unit) to simulate the detailed pounding behavior. Other columns are modeled by the two-node beam elements. The two building units are connected with a total of 70 two-node joint elements. Five elements are provided per story and arranged along the A, B, C, D, and E axes on the level of each floor slab. The relationship between stress and displacement, shown in

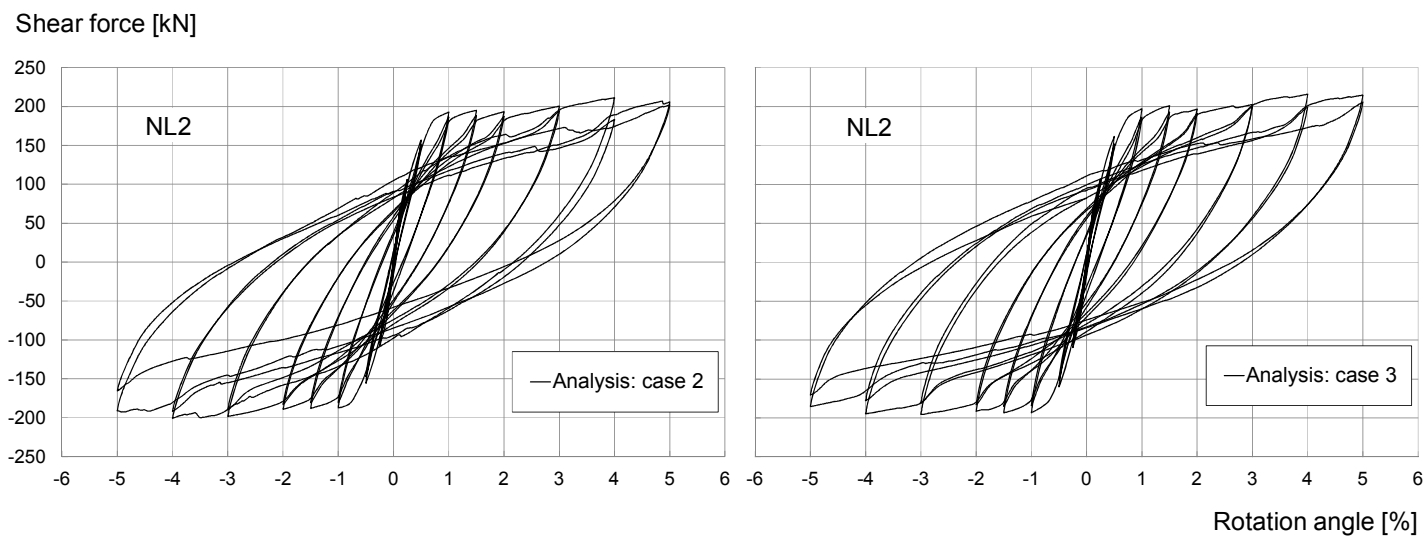

Fig. 17 Relationships between shear force and rotation angle (parametric studies). 


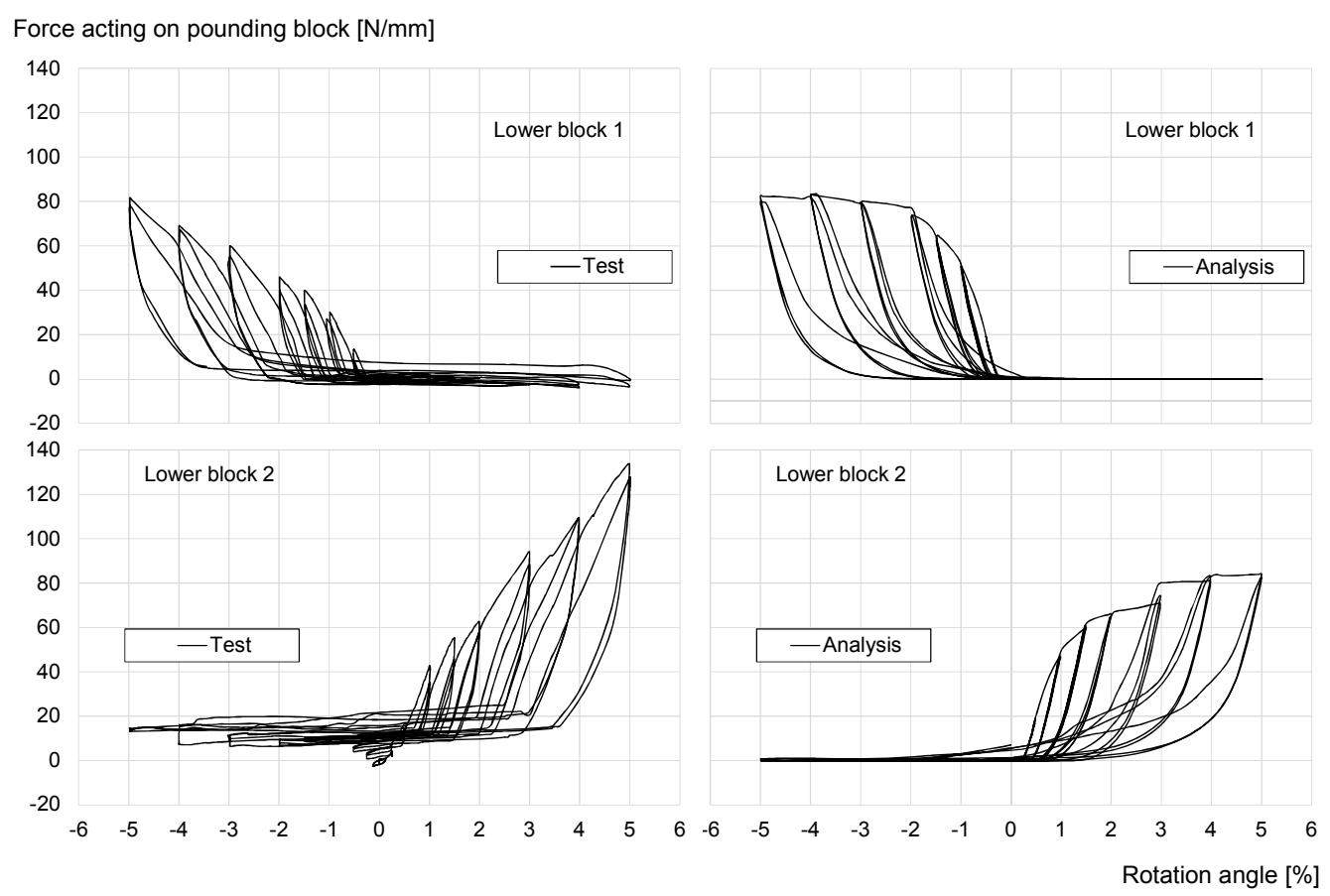

Fig. 18 Force acting on pounding block.

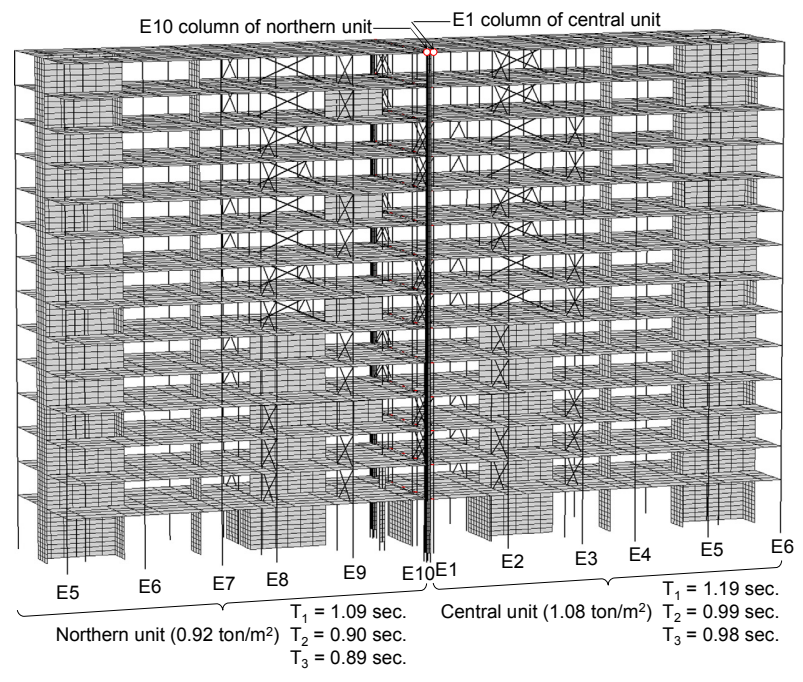

Fig. 19 Two-unit model.

Fig. 20, which is based on the Case 1 model in the previous section, is implemented into these two-node joint elements. The time history response analysis is conducted in the same manner as the preliminary analyses. To differentiate the vibration modes of the two units, the weight per a unit floor area of the northern unit is reduced to $0.92 \mathrm{ton} / \mathrm{m}^{2}$ while that of the central unit is increased to $1.08 \mathrm{ton} / \mathrm{m}^{2}$. The first three natural periods of the former are ermined as equal to: $\mathrm{T}_{1}=1.09 \mathrm{sec}$. and $\mathrm{T}_{2}=0.90 \mathrm{sec}$. and $\mathrm{T}_{3}=0.89 \mathrm{sec}$., and the latter: $\mathrm{T}_{1}$ $=1.19$ sec. and $\mathrm{T}_{2}=0.99$ sec. and $\mathrm{T}_{3}=0.98$ sec., respectively. In the Newmark- $\beta$ time integration method, uniform $1 \%$ damping is assumed for the first natural period of the basic model. The same damping is also assumed for the two-node joint elements. This means

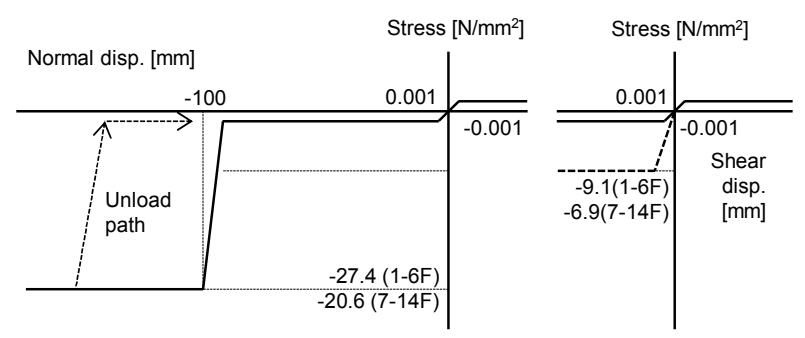

Fig. 20 Constitutive model for two-node joint element of two-unit model.

that the restitution coefficient, which is the ratio of post-collision relative velocity to the prior-collision one, is assumed almost 1.0 since considerably a small relative velocity (i.e. smaller than $0.2 \mathrm{~m} / \mathrm{s}$ ) is expected (Goldsmith 1960; Jankowski 2005, 2010).

Figure 21 shows the relationships between total deformation ratio and time in the north-south, east-west, and vertical directions. The thick line represents the displacement of the top of Column E10 of the northern unit and the thin line the top of Column E1 of the central unit as indicated in Fig. 19. After about 30 seconds, the instance of the initial pounding, the total deformation ratio in the north-south direction of the two-unit model is slightly reduced compared to the basic model in the preliminary analyses although the deformation is still significantly larger than that of the jointed model. Discrepancy is observed between the vibrations in the north-south direction of the two units, which causes the pounding. On the other hand, the vibrations in the east-west direction of the two units are almost coincided.

Figure 22 shows crack pattern and deformation of the two-unit model at 39.05 second when the maximum 
displacement is induced along east-west direction. The top view of Fig. 22 indicates that twisted deformations of the two units cause the pounding between the Column E10 of the northern unit and Column E1 of the central unit. Figure 23 shows relationships between the stress and normal displacement of the two-node joint elements connected to the top of the columns in the 14th story. The vertical axis therefore represents the stress along the longitudinal (north-south) direction of the building. Figure 23 indicates that the pounding occurs at only one of five columns, E10, in which a large compressive stress $-20.6 \mathrm{~N} / \mathrm{mm}^{2}$ is induced when the displacement reaches $-100 \mathrm{~mm}$. Note that the stresses induced in the other four elements are $0.001 \mathrm{~N} / \mathrm{mm}^{2}$, indicating an absence of pounding. Figure 24 shows the relationships between stress and displacement of two shear components of the two-node joint element of Column E10. The maximum stresses in both shear directions are 1.0 $\mathrm{N} / \mathrm{mm}^{2}$. The shear stress in the east-west direction slightly affects the east-west vibration amplitude while the shear stress in the vertical direction is supposed to reduce the vertical vibration amplitude.

Figure 25 shows the relationship between the ratio of the pounding load to the total weight of a building unit and time. In this case, the pounding load is equal to the load of normal spring of the two-node joint elements of Column E10 since pounding is only observed in this location. The pounding load is normalized by dividing by the total mass of a building unit, 9,868 tons. The maximum ratio of the pounding load to the total building mass is 0.0092 attained at the time $39.2 \mathrm{sec}$, which

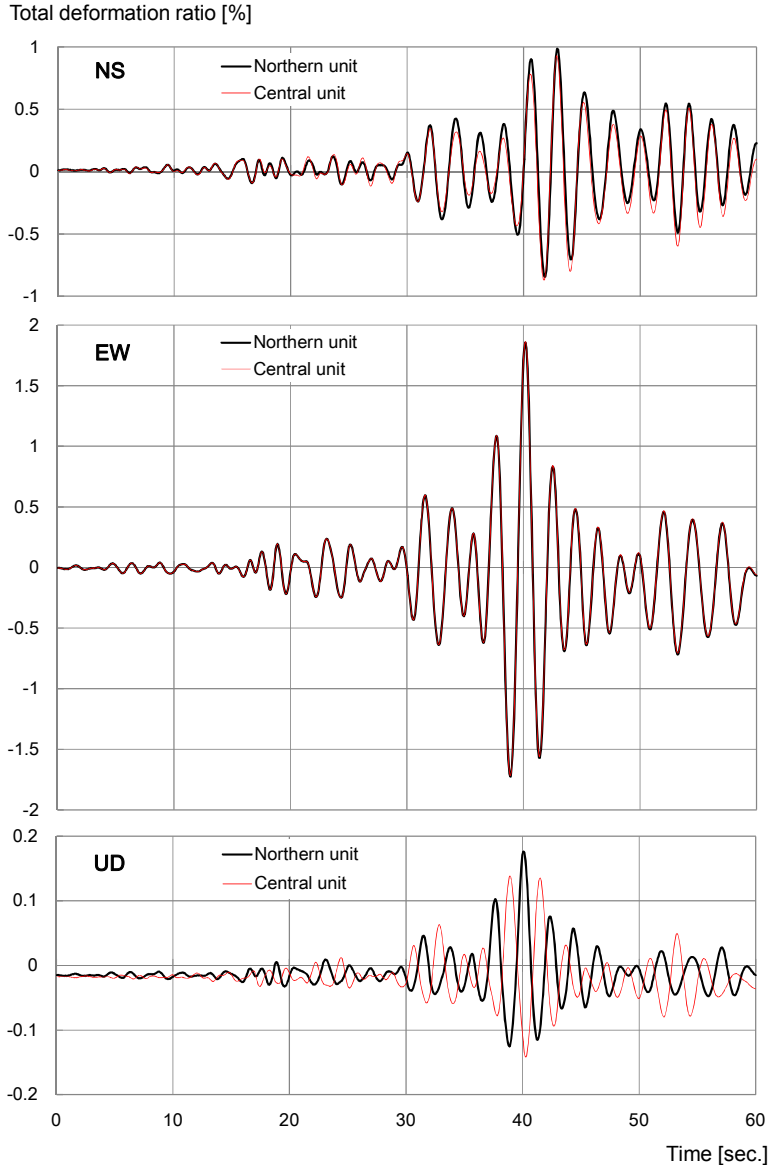

Fig. 21 Relationships between total deformation ratio and time.

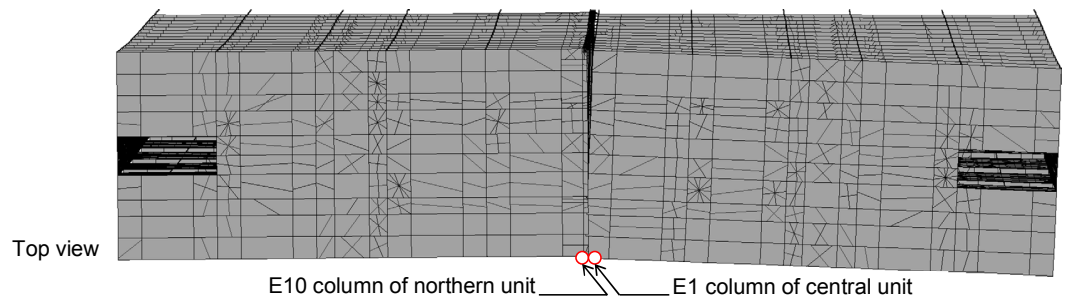

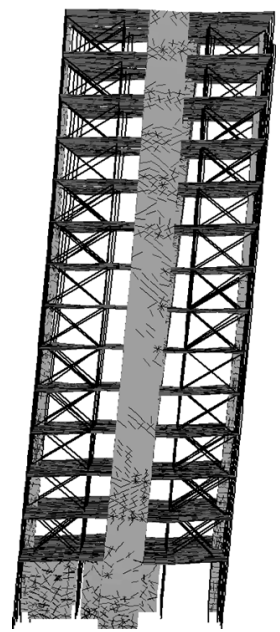

Northern view

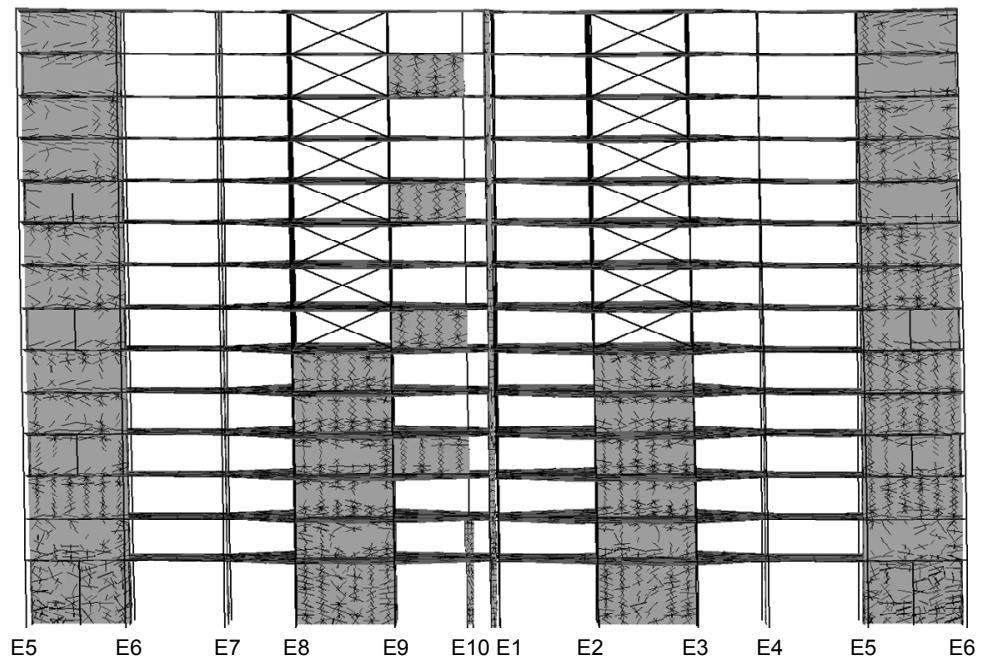

West view

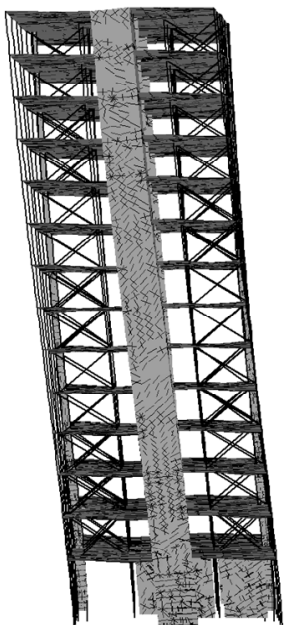

Southern view

Fig. 22 Crack pattern and deformation of two-unit model at 39.05 second. 
Table 6 Relative velocities between two units at pounding (time $=39.2$ sec. $)$.

\begin{tabular}{|c|c|c|c|}
\hline & NS & EW & UD \\
\hline Before pounding & $0.134 \mathrm{~m} / \mathrm{s}$ & $0.004 \mathrm{~m} / \mathrm{s}$ & $-0.167 \mathrm{~m} / \mathrm{s}$ \\
\hline After pounding & $-0.152 \mathrm{~m} / \mathrm{s}$ & $0.004 \mathrm{~m} / \mathrm{s}$ & $0.174 \mathrm{~m} / \mathrm{s}$ \\
\hline
\end{tabular}

is equivalent to the maximum load in the north-south direction of the basic model in the preliminary analysis. This estimation indicates that the jointed model in the preliminary analysis considerably overestimates the maximum north-south load because of the over-simplified boundary condition using the reaction plane. The pounding load ratio of 0.0092 is 2.9 times that of the flexural yield strength of Column E10 (31.5 $\mathrm{kN})$, which can be resisted by shear/flexural capacities of several adjacent columns and the collapse does not occur in this analysis.

Table 6 shows the relative velocities between the two units before and after the pounding at the time $39.2 \mathrm{sec}$. In the pounding direction (NS), the two units approach in a velocity of $0.134 \mathrm{~m} / \mathrm{s}$ and leave in $0.152 \mathrm{~m} / \mathrm{s}$ after the collision. According to Jankowski's research (Jankowski 2010), the restitution coefficient of the concrete materials becomes greater than 0.75 if the

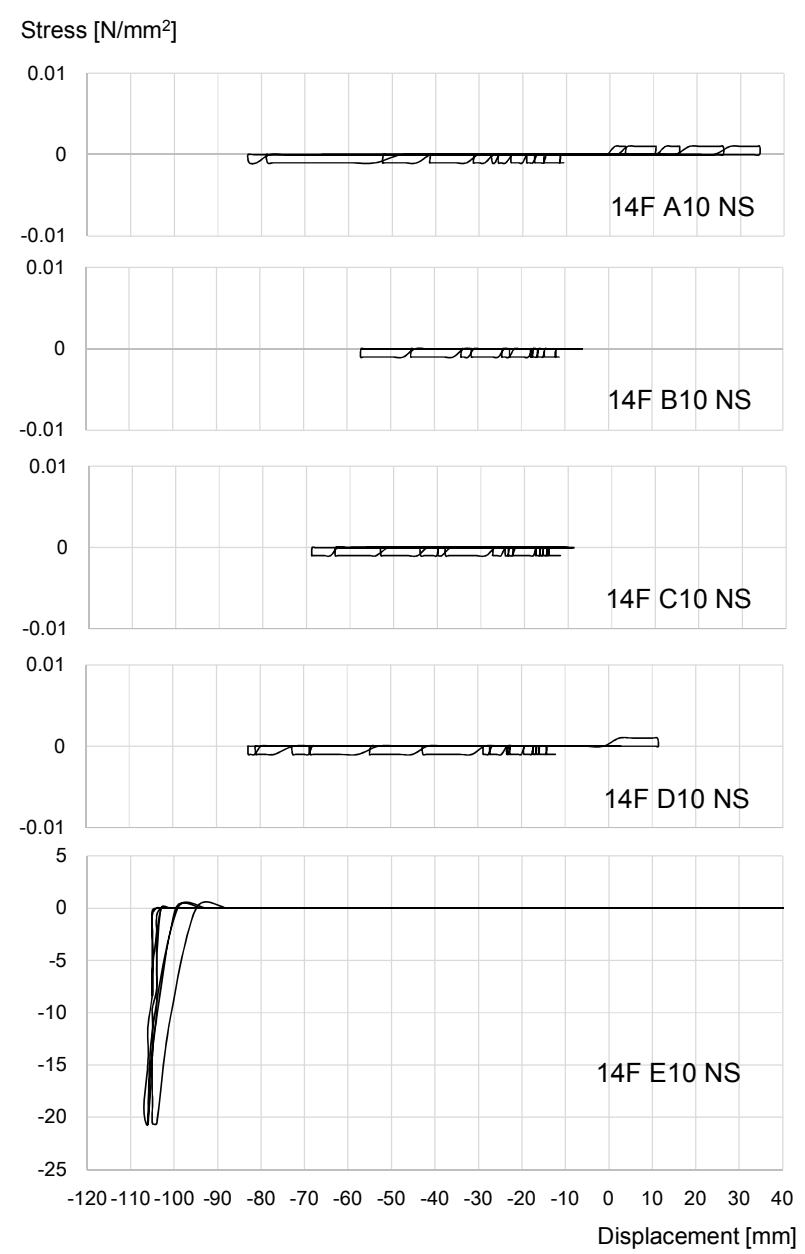

Fig. 23 Relationships between stress and displacement of two-node joint element (two-unit model). prior-pounding velocity is smaller than $0.2 \mathrm{~m} / \mathrm{s}$. The relative velocities in this analysis indicate that the velocity is not always reduced after the pounding. The reversed relative UD velocities $(-0.167 \mathrm{~m} / \mathrm{s}$ and 0.174 $\mathrm{m} / \mathrm{s}$ ) in Table 6 indicate that the friction occurs along the up-down direction while the unchanged $\mathrm{EW}$ velocities $(0.004 \mathrm{~m} / \mathrm{s}$ and $0.004 \mathrm{~m} / \mathrm{s})$ indicate no friction in the transverse direction. The friction in UD direction corresponds to the negative shear stress indicated in Fig. 24 (14F E10UD).

\section{Conclusions}

Seismic response of a 14-story reinforced concrete building, Nuevo León, damaged in 1985 Mexico Earthquake is investigated by means of dynamic finite element analyses and cyclic loading test of column specimens. The following remarks are made based on this research.

1. Time history response analysis of the single building unit model indicates that the natural period is elongated by more than twice and resonance with the ground motion occurs.

2. Experimental tests are conducted with the two column specimens to observe the influence of con-

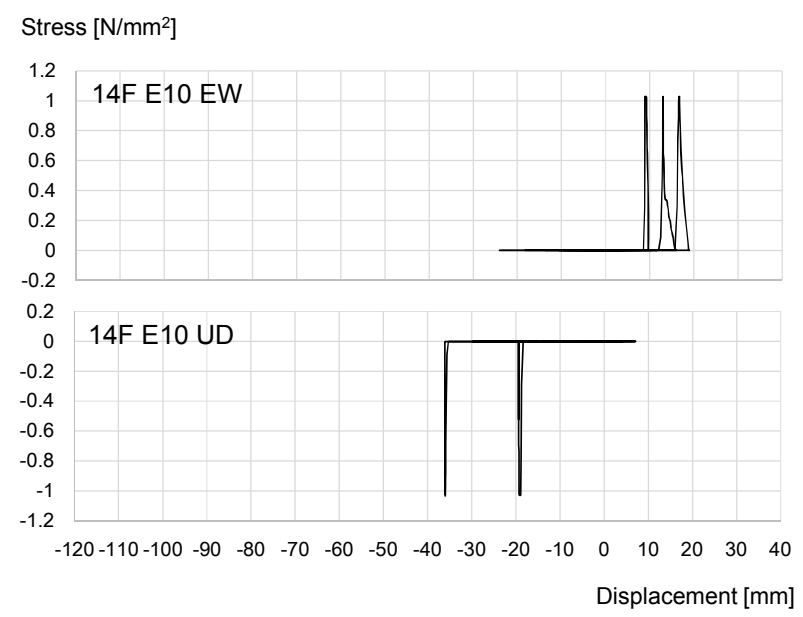

Fig. 24 Relationships between stress and displacement of two-node joint element (two-unit model; shear directions).

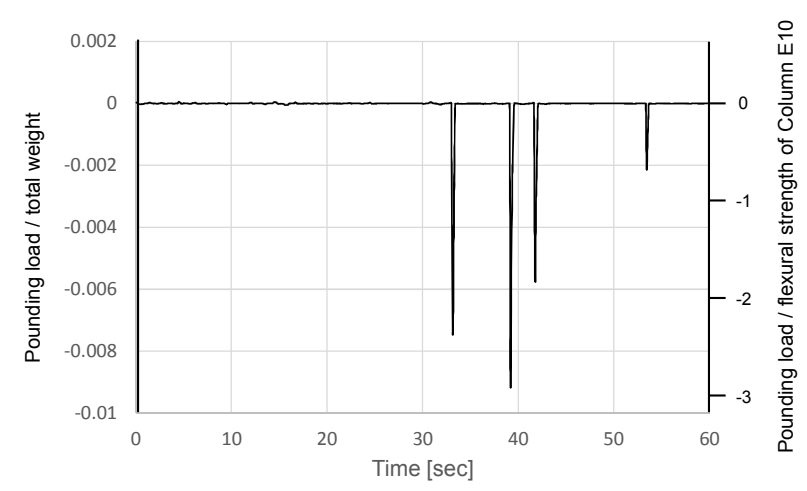

Fig. 25 Relationship between ratio of pounding load to total weight and time. 
tact/friction between adjacent columns on the shear/flexural behaviors. The presence of the contact/friction increased the shear force applied to the column specimen by $30 \%$.

3. Finite element analyses of the two column specimens are conducted and a constitutive model of the local contact/friction behavior is developed.

4. The above-mentioned constitutive model is implemented to a finite element model of the two adjacent building units and a time history response analysis is conducted. The evaluated pounding load induced between the building units is 0.0092 times the total weight. This load is 2.9 times the flexural strength of the column on the 14th story although it is resisted by the shear/flexural capacities of several adjacent columns.

5. The analysis of two-unit model indicates that the relative velocity after the pounding is not always reduced comparing to the prior-pounding velocity. The analysis also indicates that the pounding is accompanied with the friction in the transverse and up-down directions.

The impact load may be varied if a considerable difference in period elongation occurs between adjacent building units. The period-elongation characteristics and the contact/friction characteristics are under investigation and will be discussed in the next paper.

This work is supported by MEXT / JSPS KAKENHI Grant-in-Aid for Scientific Research (C), 15K06292.

\section{References}

AIJ, (1987). "Report on disaster investigations of 1985 Mexico Earthquake." Architectural Institute of Japan, (in Japanese).

Anagnostopoulos, S. A. and Spiliopoulos, K. V. (1992). "An investigation of earthquake induced pounding between adjacent buildings." Earthquake Engineering and Structural Dynamics, 21, 289-302.

Anagnostopoulos, S. A. (1998). "Pounding of buildings in series during earthquakes." Earthquake Engineering and Structural Dynamics, 16, 443-456.

Anagnostopoulos, S. A. and Karamaneas, C. E., (2008). "Use of collision shear walls to minimize seismic separation and to protect adjacent buildings from collapse due to earthquake-induced pounding." Journal of Earthquake Engineering and Structural Dynamics, 37, 1371-1388.

Bertero, V. V., (1986). "Observations on structural pounding." Proceedings of the International Conference on Mexico Earthquakes, ASCE: New York, 264-287.

Burrell, R. P., Aoude, H. and Saatcioglu, M., (2015). "Response of SFRC columns under blast loads." ASCE Journal of Structural Engineering, 141(9), DOI: 10.1061/(ASCE)ST.1943-541X.0001186.

Chau, K. T. and Wei, X. X., (2001). "Pounding of structures modelled as non-linear impacts of two oscillators." Earthquake Engineering and Structural
Dynamics, 30, 633-651.

Ciampi, V., Eligehausen, R., Bertero, V. V. and Popov, E. P., (1982). "Analytical model for concrete anchorages of reinforcing bars under generalized excitations." Report No. UCB/EERC-82/23, Univ. of California, Berkeley.

Cole, G. L., Dhakal R. P., Carr, A. J. and Bull, D. K., (2010). "Interbuilding pounding damage observed in the 2010 Darfield earthquake." Bulletin of the New Zealand Society for Earthquake Engineering 2010, 43(4), 382-386.

Cole, G. L., Dhakal R. P. and Turner, F. M., (2014). "Building pounding damage observed in the 2011 Christchurch earthquake." Earthquake Engineering and Structural Dynamics, 41, 893-913.

Dat, P. X. and Tan, K. H., (2015). "Experimental response of beam-slab substructures subject to penultimate-external column removal." $A S C E$ Journal of Structural Engineering, 141(7), DOI: 10.1061/(ASCE)ST.1943-541X.0001123.

Davis, R. D., (1992). "Pounding of buildings modelled by an impact oscillator." Journal of Earthquake Engineering and Structural Dynamics, 21, 253-274.

fib, (2010). "fib model code 2010." Fédération Internationale de la Précontrainte, Lausanne, Switzerland, 233-239.

Fujikake, K., Senga, T., Ueda, N., Ohno, T. and Katagiri, M., (2006). "Study on impact response of reactive powder concrete beam and its analytical model." Journal of Advanced Concrete Technology, 4(1), 99-108.

Ghannoum, W. M. and Moehle, J. P., (2012a). "Shake-table tests of a concrete frame sustaining column axial failures." ACI Structural Journal, 109(3), 393-402.

Ghannoum, W. M. and Moehle, J. P., (2012b). "Dynamic collapse analysis of a concrete frame sustaining column axial failures." ACI Structural Journal, 109(3), 403-412.

Goland, M., Wickersham, P. D. and Dengler, M. A., (1955). "Propagation of elastic impact in beams in bending." Journal of Applied Mechanics, 22, 1-7.

Goldsmith, W., (1960). "Impact: The theory and physical behaviour of colliding solids." 1 st edition, Edward Arnold, London, U.K.

Isobe, D., Ohta, T., Inoue, T. and Matsuda, F., (2012). "Seismic pounding and collapse behavior of neighboring buildings with different natural periods." Natural Science, 4(8A), DOI:10.4236/ns.2012.428090.

Jankowski, R, Wilde K, Fujino Y., (1998). "Pounding of superstructure segments in isolated elevated bridge during earthquakes." Earthquake Engineering and Structural Dynamics, 27, 487-502.

Jankowski, R., (2005). "Non-linear viscoelastic modelling of earthquake-induced structural pounding." Earthquake Engineering and Structural Dynamics, 34, 595-611.

Jankowski, R., (2006). “Analytical expression between 
the impact damping ratio and the coefficient of restitution in the non-linear viscoelastic model of structural pounding." Earthquake Engineering and Structural Dynamics, 35, 517-524.

Jankowski, R., (2009). "Non-linear FEM analysis of earthquake-induced pounding between the main building and the stairway tower of the Olive View Hospital." Engineering Structures, 31, 1851-1864.

Jankowski, R., (2010). "Experimental study on earthquake-induced pounding between structural elements made of different building materials." Earthquake Engineering and Structural Dynamics, 39, 343-354.

Jing, H. - S. and Young, M., (1991). "Impact interactions between two vibration systems under random excitation." Earthquake Engineering and Structural Dynamics, 20, 667-681.

Kasai, K. and Maison, B. F., (1997). "Building pounding damage during the 1989 Loma Prieta earthquake." Engineering Structures, 19(3), 195-207.

Kim, I., Jirsa, J. O. and Bayrak, O., (2015). "Use of carbon fiber-reinforced polymer to provide continuity in reinforced concrete beams under dynamic loading." ACI Structural Journal, 112(3), DOI: $10.14359 / 51687423$.

Kumazawa, S., Soga, K. and Mori, A., (2013). "Earthquake response characteristics of a 30-story RC building." Summaries of Annual Meeting of AIJ, Sapporo, Architectural Institute of Japan, 629-632, (in Japanese).

Liu, J., Tian, Y., Orton, S. L. and Said, A. M., (2015a). "Resistance of flat-plate buildings against progressive collapse. I: Modeling of slab-column connections." ASCE Journal of Structural Engineering, 141 (12), DOI: 10.1061/(ASCE)ST.1943-541X.0001294.

Liu, J., Tian, Y. and Orton, S. L., (2015b). "Resistance of flat-plate buildings against progressive collapse II: System response." ASCE Journal of Structural Engineering, 141(12), DOI: 10.1061/(ASCE)ST.1943$541 X .0001295$.

Maison, B. F. and Kasai, K., (1992). "Dynamics of pounding when two buildings collide." Journal of Earthquake Engineering and Structural Dynamics, 21, 771-786.

Masi, A. and Vona, M., (2010). "Experimental and numerical evaluation of the fundamental period of undamaged and damaged RC framed buildings." Bull Earthquake Eng, 8, 643-656.

Naganuma, K., Yonezawa, K., Kurimoto, O. and Eto, H., (2004). "Simulation of nonlinear dynamic response of reinforced concrete scaled model using three-dimensional finite element method." Proceedings of the 13th World Conference on Earthquake Engineering, Paper No.586.

Nagae, T., Ghannoum, W. M., Kwon, J., Tahara, K., Fukuyama, K., Matsumori, T., Shiohara, H., Kabeyasawa, T., Kono, S., Nishiyama, M., Sause, R., Wallace, J. W. and Moehle, J. P., (2015). "Design im- plications of large-scale shake-table test on four-story reinforced concrete building." ACI Structural Journal, 112(2), 135-146, DOI: 10.14359/51687421.

Pantelides, C. P. and Ma, X., (1998). "Linear and nonlinear pounding of structural systems." Computers and Structures, 66, 79-92.

Prasad, S. and Hutchinson, T. C., (2014). "Evaluation of older reinforced concrete floor slabs under corner support failure." ACI Structural Journal, 111(4), 839-849.

Qian, K. and Li, B., (2015a). "Strengthening of multibay reinforced concrete flat slabs to mitigate progressive collapse." ASCE Journal of Structural Engineering, 141(6), DOI: 10.1061/(ASCE)ST.1943 $-541 X .0001125$.

Qian, K., Li, B. and Ma, J. X., (2015b). "Load-carrying mechanism to resist progressive collapse of RC buildings." ASCE Journal of Structural Engineering, 141(2), DOI: 10.1061/(ASCE)ST.1943-541X.0001046.

Rodriguez, M. E., Santiago, S. and Meli, R., (1995). "Seismic load tests on two-story waffle-flat-plate structure." ASCE Journal of Structural Engineering, 121(9), 1287-1293.

Rodriguez, M. E. and Santiago, S., (1998). "Simulated seismic load tests on two-story waffle-flat-plate structure rehabilitated by jacketing." ACI Structural Journal, 95(2), 129-138.

Saatci, S. and Vecchio, F. J., (2009). "Nonlinear finite element modeling of reinforced concrete structures under impact loads." ACI Structural Journal, 106(5), 717-725

Salem, H., Mohssen, S., Kosa, K. and Hosoda, A., (2014). "Collapse analysis of Utatsu Ohashi Bridge damaged by Tohuku Tsunami using applied element method." Journal of Advanced Concrete Technology, 12, 383-402.

Sato, Y. and Naganuma, K., (2007). "Discrete-like crack simulation by smeared crack-based FEM for reinforced concrete." Journal for Earthquake Engineering and Structural Dynamics, 36, 2137-2152, DOI: 10.1002/eqe.720.

Sato, Y. and Naganuma, K., (2014). "Discrete-like crack simulation of reinforced concrete incorporated with analytical solution of cyclic bond model." ASCE Journal of Structural Engineering, 140(3), 109-116.

Scholl, R. E., (1989). “Observations of performance of buildings during the 1985 Mexico Earthquake, and structural design implications." International Journal of Mining and Geographical Engineering, 7, 69-99.

van Mier, J. G. M., Pruijssers, A. F., Reinhardt, H. W. and Monnier, T., (1991). "Load-time response of colliding concrete bodies." ASCE Journal of Structural Engineering, 117, 354-374.

Valles R. E. and Reinhorn A. M., (1997). "Evaluation, prevention and mitigation of pounding effects in building structures." Technical Report NCEER-97-0001, 
National Center for Earthquake Engineering Research, State University of New York at Buffalo, U.S.A.

Yi, N. H., Choi, J. H., Kim, S. J. and Kim, J. H. J., (2015). "Collision capacity evaluation of RC columns by impact simulation and probabilistic evaluation" Journal of Advanced Concrete
Technology, 13, 67-81.

Zhu, P., Abe, M. and Fujino, Y., (2002). "Modelling three-dimensional non-linear seismic performance of elevated bridges with emphasis on pounding of girders." Earthquake Engineering and Structural Dynamics, 31, 189-1913. 